\title{
C1QTNF3 in the murine ovary and its function in folliculogenesis
}

\author{
Zhoufei Mao',*, Liuhong Yang,*, Xiaosheng Lu,*, Anni Tan¹, Yuxia Wang², Fei Ding ${ }^{1}$, \\ Luanjuan Xiao ${ }^{1}$, Xufeng Qi ${ }^{1}$ and Yanhong Yu ${ }^{1}$ \\ ${ }^{1}$ Key Laboratory for Regenerative Medicine (JNU-CUHK), Ministry of Education, Department of Developmental and \\ Regenerative Biology, College of Life Science and Technologies, Jinan University, Guangzhou, China and \\ ${ }^{2}$ Department of Reproductive Medicine, The First Affiliated Hospital, Jinan University, Guangzhou, China \\ Correspondence should be addressed to Y Yu; Email: yuyhong79@gmail.com
}

*(Z Mao, L Yang and X Lu contributed equally to this work)

\begin{abstract}
C1q/tumor necrosis factor-related protein 3 (C1QTNF3) is a novel adipokine with modulating effects on metabolism, inflammation and the cardiovascular system. C1QTNF3 expression levels in the sera and omental adipose tissues of women with PCOS are low compared to control subjects. However, the expression and function of C1QTNF3 in the ovary has not previously been examined. Here, we assessed the expression patterns of C1qtnf3 in the ovary and explored its role in folliculogenesis. The C1qtnf3 transcript abundance was higher in large follicles than in small follicles and was under the influence of gonadotropin. C1QTNF3 was detected mainly in the granulosa cells and oocytes of growing follicles and modestly in the granulosa cells of atretic follicles and in luteal cells. Excess androgen significantly decreased C1QTNF3 expression in the ovaries in vivo and in granulosa cells in vitro. Recombinant C1QTNF3 protein accelerated the weight gain of ovarian explants and the growth of preantral follicles induced by follicle stimulating hormone (FSH) in vitro. The stimulatory effect of C1QTNF3 on ovarian growth was accompanied by the initiation of AKT, mTOR, p70S6K and 4EBP1 phosphorylation, an increase in CCND2 expression and a reduction in cleaved CASP3 levels. Moreover, the addition of C1QTNF3 accelerated proliferation and reduced activated CASP3/7 activity in granulosa cells. In vivo, the ovarian intrabursal administration of the C1QTNF3 antibody delayed gonadotropin-induced antral follicle development. Taken together, our data demonstrate that C1QTNF3 is an intraovarian factor that promotes follicle growth by accelerating proliferation, decelerating apoptosis and promoting AKT/mTOR phosphorylation.

Reproduction (2018) $155333-346$
\end{abstract}

\section{Introduction}

C1q/tumor necrosis factor-related protein 3 (C1QTNF3, also known as CTRP3, cartonectin, cartducin and CORS-26) belongs to a family of CTRPs, which are paralogs of adiponectin and which comprise a collagenous region and $\mathrm{C} 1 \mathrm{q}$-like globular domains (Wong et al. 2004). C1QTNF3 is widely distributed in the tissues of primates and rodents, and its transcript is detected in adipose tissue, cartilage, the kidney, placental tissue, the pancreas, the small intestine, the colon, the brain, the thymus and the ovary; moreover, C1QTNF3 protein is expressed in the heart, liver, muscle and kidney (Peterson et al. 2010, Schaffler \& Buechler 2012, Otani et al. 2012). C1QTNF3 participates in multiple biological effects, such as regulating adipokine secretion and promoting cell proliferation and differentiation (Maeda et al. 2006, Akiyama et al. 2007, Maeda \& Wakisaka 2010, Hou et al. 2015, Otani et al. 2015). C1QTNF3 also regulates glucose and lipid metabolism (Peterson et al. 2010, 2013), attenuates the inflammatory response (Schmid et al. 2014), and reduces cell apoptosis (Yi et al. 2012, Hou et al. 2014, 2015). Recently, Iysosomal-associated membrane protein 1 (LAMP-1) and lysosome membrane protein 2 (LIMP II) were reported to be the putative receptors of C1QTNF3 (Li et al. 2016). C1QTNF3 is considered a beneficial adipokine because its circulating levels are significantly lower in humans with obesity, hypertension and type 2 diabetes (Ban et al. 2014, Deng et al. 2015, Wolf et al. 2015).

Polycystic ovarian syndrome (PCOS) is the most common endocrinopathy affecting women and is a leading cause of female infertility worldwide. PCOS represents a state of hormonal dysregulation, disrupted ovarian follicle dynamics and subsequent oligoovulation or anovulation. Aberrant folliculogenesis is the main characteristic of PCOS and is associated with an abnormal environment controlled by complex interactions between extraovarian signals, including 
gonadotropins and metabolic factors, and locally produced growth factors (Franks etal.2008). Adiponectin, the paralog of C1QTNF3, is reportedly associated with abnormal folliculogenesis in women with PCOS (Tao et al. 2013). Female adiponectin-null mice display impaired fertility, reduced oocyte retrievals, disrupted estrous cycles, elevated numbers of atretic follicles and impaired late folliculogenesis (Cheng et al. 2016). Many studies have shown that C1QTNF3 has similar functions to those of adiponectin, such as attenuating diet-induced hepatic steatosis (Xu et al. 2003, Peterson et al. 2013), protecting the heart from ischemic injury (Shibata et al. 2005, Yi et al. 2012), reducing cell apoptosis (Yi et al. 2012, Hou et al. 2014, Tian et al. 2016) and attenuating inflammation (Ajuwon \& Spurlock 2005, Schmid et al. 2014). Recent studies have shown that C1QTNF3 levels in the sera and omental adipose tissues of women with PCOS are lower than those of control subjects and that metformin treatment increases serum C1QTNF3 levels (Tan et al. 2013), in a similar manner to adiponectin. These findings have motivated us to hypothesize that C1QTNF3 plays a role in the abnormal folliculogenesis of PCOS ovaries.

Although C1QTNF3 transcripts are present in human ovarian tissues, the C1QTNF3 protein distributions and cellular expression patterns remain unknown. Moreover, the role of C1QTNF3 in follicular development has not been investigated. The aim of the current study was to determine (1) the presence and expression patterns of C1QTNF3 in murine ovaries; (2) whether the low level of C1QTNF3 in PCOS was induced by excess androgen and (3) whether C1QTNF3 was involved in the regulation of follicular development.

\section{Materials and methods}

\section{Animals}

Kunming (KM) white female mice were purchased from GuangDong Medical Laboratory Animal Centre, Guangzhou, China, and maintained in $22-24^{\circ} \mathrm{C}$ rooms on 14 -h light, 10-h darkness cycles and given food and water ad libitum. All procedures were carried out in accordance with the Guidelines for the Care and Use of Laboratory Animals, and all animal experimental protocols were approved by the animal experimental ethics committee of Jinan University.

The PCOS mouse model was produced in mice by injection of DHEA as previously described (Motta 2010). Briefly, 21-day-old prepubertal female KM strain mice were daily injected (s.c.) with DHEA ( $6 \mathrm{mg} / 100 \mathrm{~g}$ body weight, dissolved in $0.01 \mathrm{~mL} 95 \%$ ethanol and mixed with $0.09 \mathrm{~mL}$ sesame oil) for 23 consecutive days (DHEA-treated PCOS group, $n=15$ ). The control group mice were injected with $0.09 \mathrm{~mL}$ sesame oil and $0.01 \mathrm{~mL} 95 \%$ ethanol daily for 23 consecutive days (vehicle group, $n=15$ ). The estrus cycle stage was determined by microscopic analyzing the predominant cell types obtained via the vaginal smears taken daily from last week to the end of experiment. At the end of treatment, the mice were killed, and the ovaries were dissected for morphology and immunoblot analyses.

\section{Reverse transcription-polymerase chain reaction and quantitative real-time PCR (qPCR)}

For analyzing the transcript abundances of C1qtnf3 in the whole ovary at different developmental stages, ovaries from three mice aged 3, 10, 21 and 56 days old were dissected out of ovarian bursa, and total RNA of each ovary was extracted using the QIAGEN RNeasy mini kit (Qiagen Sciences).

For analyzing the transcript abundances of C1qtnf3 in the different ovarian cell types, the ovaries from 7- and 11-dayold mice were treated with $0.25 \%$ trypsin, $0.1 \%$ collagenase I, $0.02 \%$ DNase I for $15 \mathrm{~min}$ at $37^{\circ} \mathrm{C}$. After addition of $1 \mathrm{mM}$ EDTA, the ovaries were incubated at $37^{\circ} \mathrm{C}$ for $30 \mathrm{~min}$, and then the oocytes and remaining somatic cells were collected. In addition, the follicles were isolated from mice aged 14, 17, 20, 23 days old and from 25-day-old mice that is obtained by 23-day-old mice intraperitoneal injected with pregnant mare serum gonadotropin (PMSG) for $48 \mathrm{~h}$, and punctured to collect granulosa cells and oocytes. Meanwhile, theca cells were obtained by scraping the remaining follicles and washed with DMEM/F12 medium for 2 times. The purities of different cell types were confirmed by reverse transcription-polymerase chain reaction (RT-PCR) using specific markers, growth differentiation factor 9 (Gdf9) for oocyte, follicle-stimulating hormone receptor (Fshr) for granulosa cells or somatic cells and cytochrome P450, family 17, subfamily A, polypeptide 1 (Cyp17a1) for theca cells.

Because follicular development is accompanied by the diameter expansion, we further isolated follicles of $60 \sim 160 \mu \mathrm{m}$ in diameter from 12-day-old mice, 200 400 $\mu \mathrm{m}$ in diameter from 23-day-old mice and 500 600 $\mu \mathrm{m}$ in diameter from 56-day-old mice and detected the abundances of C1qtnf3 transcript during follicular development. Then, the total RNA of different size follicles were extracted using an RNeasy Micro Kit, and the transcript abundances of C1qtnf3 in different size follicles was analyzed.

For analyzing the effect of gonadotropin on the transcript abundances of intraovarian C1qtnf3, 21-day-old mice were injected with PMSG (5IU/each mouse) to induce follicle maturation, following at $48 \mathrm{~h}$ with an injection of human chorionic gonadotropin (hCG, 5IU/each mouse) to induce ovulation. In each time point, three mice were killed and total RNA of each mouse was extracted separately using the QIAGEN RNeasy mini kit.

First-strand cDNA was synthesized using ReverTra Ace qPCR RT kit (Toyoba, Osaka, Japan). qPCR was performed on each sample in triplicates using the QuantiTect SYBR Green Real-Time PCR kit (Toyoba). The primers used in this study are shown in Table 1. The program used to analyze the transcript abundances of C1qtnf3 in different size follicles and ovarian cells was $5 \mathrm{~min}$ at $95^{\circ} \mathrm{C}$, then 45 cycles of $15 \mathrm{~s}$ at $95^{\circ} \mathrm{C}$ and $60 \mathrm{~s}$ at $60^{\circ} \mathrm{C}$ on Bio-Rad Real-Time PCR system. Other samples were amplified for 40 cycles. Relative quantification of gene expression was determined using the comparative $\Delta \mathrm{Ct}$ method and relative expression was normalized to housekeeping gene $\beta$-actin (Actb), as previously described (Sato et al. 2012). 
Table 1 Primers used in RT-PCR and qPCR analysis.

\begin{tabular}{|c|c|c|c|c|}
\hline \multirow{2}{*}{$\begin{array}{l}\text { Target gene } \\
\text { C1qtnf3 }\end{array}$} & \multirow{3}{*}{$\begin{array}{l}\text { GenBank accession number } \\
\text { NM_001204134 }\end{array}$} & \multicolumn{2}{|c|}{ Primer sequence $\left(5^{\prime}-3^{\prime}\right)$} & \multirow{2}{*}{$\frac{\text { Position of primers (nt) }}{2035-2056}$} \\
\hline & & Forward & GGCAGACAAATGGATGCAAAGT & \\
\hline & & Reverse & TAGGCAAAAACCATCTAGCACCT & $2188-2210$ \\
\hline \multirow[t]{2}{*}{ Fshr } & NM_013523 & Forward & TCTAACAGGGTCTTCСТCTGC & 139-159 \\
\hline & & Reverse & СTCAGTTCAATGGCGTTCC & $200-218$ \\
\hline \multirow[t]{2}{*}{ Gdf9 } & NM_008110 & Forward & CCAGAGGACGGAGTGTTTAGC & $832-852$ \\
\hline & & Reverse & TCТTTCСАССТСАATAGСТTCC & 999-1020 \\
\hline \multirow[t]{2}{*}{ Cур17a1 } & NM_007809 & Forward & CCAGGACCCAAGTGTGTTCT & 997-1016 \\
\hline & & Reverse & ССТGATACGAAGCACTTCTCG & $1226-1246$ \\
\hline \multirow[t]{2}{*}{ Actb } & NM_007393 & Forward & СТTTTCСАGССТTССТTСТTGG & 890-911 \\
\hline & & Reverse & CAGCACTGTGTTGGCATAGAGG & 985-1006 \\
\hline
\end{tabular}

\section{Histochemistry and immunohistochemistry}

The ovaries were fixed with $4 \%$ paraformaldehyde and embedded in the paraffin. After the ovaries were longitudinally and serially sectioned at $5 \mu \mathrm{m}$, the sections were placed onto L-lysine treated slides. Serial sections were deparaffinized and hydrated, and then stained with hematoxylin and eosin for analyzing ovarian morphology and the proportion of follicles at different developmental stages.

Immunohistochemical analysis was performed to detect the distribution of C1QTNF3 in the ovary. Briefly, sections were treated as follows: microwave antigen retrieval $(700 \mathrm{~W}$ for $7 \mathrm{~min}$, twice in $10 \mathrm{mM}$ sodium citrate, $\mathrm{pH} 6.0$ ); $3 \%$ hydrogen peroxide to block endogenous peroxidase and $10 \%$ normal goat serum to block non-specific bindings. C1QTNF3 was detected with C1QTNF3 antibody (Ab) (1:400, Abcam, Cat. No. ab36870) and horseradish peroxidase (HRP)-labeled anti-rabbit IgG (1:1000, Sigma-Aldrich, Cat. No. A0545). 3, 3'-diaminobenzidine tetrahydrochloride was used to chromomeric reaction and hematoxylin was used to stain the nucleus. The staining of C1QTNF3 signals was examined by Leica DFC300 FX microscope. For the negative control, the primary Ab was replaced by normal rabbit serum.

\section{Ovarian explant culture}

Ovarian explants were cultured as previously described (Sato et al. 2012). Briefly, the whole ovaries from 10- or 12-day-old mice were placed on $0.4 \mu \mathrm{m}$ culture plate inserts (Millipore) and cultured in $400 \mu \mathrm{L}$ of DMEM/F12 containing $0.1 \%$ BSA, $0.1 \%$ Albumax II, 5x insulin-transferrin-selenium (Gibco, Thermo Fisher Scientific), $0.05 \mathrm{mg} / \mathrm{mL}$ L-ascorbic acid and penicillinstreptomycin under the membrane insert to cover ovaries with a thin layer of medium. Ovaries were treated with FSH $(0.25 \mathrm{IU} /$ $\mathrm{mL}$, Ningbo Secondary Hormone, Ningbo, China) or 0, 1, 3 and $10 \mu \mathrm{g} / \mathrm{mL}$ recombinant mouse globular domain of C1QTNF3 (gC1QTNF3) or full-length C1QTNF3 protein (fC1QTNF3) (Aviscera Bioscience, Santa Clara, CA, USA) or a combination treatment of FSH and C1QTNF3. Ovaries were cultured at $37^{\circ} \mathrm{C}$ in a humidified atmosphere containing $5 \% \mathrm{CO}_{2}$ for 4 days, and the medium containing C1QTNF3 protein were changed every 2 days, while $\mathrm{FSH}$ was added to the medium every day. In each treatment group, 8 22 ovaries were used for paired culture. At the end of culture, ovaries were collected for morphological assessment and follicular counting, qPCR or Western blot analysis. To detect the activation of molecules and signal pathways stimulated by gC1QTNF3 and/or FSH treatment, ovaries of 12-day-old mice were cultured in the medium containing gC1QTNF3 $(3 \mu \mathrm{g} / \mathrm{mL})$, FSH $(0.25 \mathrm{IU} / \mathrm{mL})$ or gC1QTNF3 $(3 \mu \mathrm{g} / \mathrm{mL})$ plus $\mathrm{FSH}(0.25 \mathrm{IU} / \mathrm{mL})$ for $30 \mathrm{~min}$ and $60 \mathrm{~min}$ (for phosphorylation detection) or for $48 \mathrm{~h}$ and $96 \mathrm{~h}$ (for CCDN2 and CASP3 detection), and then collected for qPCR or Western blot analysis.

\section{Follicle counting and diameter measure}

To assess whether the follicles were growing and progressing during folliculogenesis, the follicle numbers from each follicular stage were counted. For the preantral follicles counting, the first and third sections of every alternate slide were used for counting. Follicles with one oocyte surrounded by a single layer of flattened granulosa cells were scored as primordial follicles, follicles with an oocyte surrounded by one layer of cubical granulosa cells were considered as primary, follicles with an oocyte surrounded by two layers of granulosa cells were considered as early secondary, follicles with multilayers of granulosa cells but without an antrum were considered as later secondary (Johnson et al. 2004, Myers et al. 2004, Sato et al. 2012). Only follicles with clearly stained oocyte nuclei were counted to prevent recounting of the same follicle. If the oocyte was of degenerate appearance, or was fragmenting, the follicle was scored as atretic (Johnson et al. 2004, Uslu et al. 2017). For antral follicular counting, every 5th section was counted. A follicle that was roughly round in appearance with an intact, non-fragmenting oocyte was scored as intact antral follicle. A follicle that either contained a fragmenting oocyte, or, was misshapen (e.g., is not subjectively round), was scored atretic antral follicles (Uslu et al. 2017). Early antral follicles have emerging antral spaces, whilst later antral follicles possessed a clearly defined antral space (Johnson et al. 2004, Myers et al. 2004). Preovulatory follicles, which were the largest of the follicular types and possessed a defined cumulus granulosa cell layer, were classed into the later antral follicles. A percentage distribution was determined for each follicle class in different treatment group. Follicle diameters were measured with Image Pro Plus 6.0 (Wu et al. 2014). Follicle counting and diameter measure were performed by blinded operators to avoid any biases.

\section{Preantral follicle isolation and culture}

We further investigated the effect of gC1QTNF3 on follicular development by in vitro preantral follicles culture system. Preantral follicles $(90 \sim 160 \mu \mathrm{m})$ were mechanically dissected 
from the ovaries of 11- 14-day-old mice and cultured individually in 96-well microliter-plates containing DMEM/ F12 $(100 \mu \mathrm{L} /$ well $)$ with $0.1 \%$ BSA, insulin-transferrin-selenium, $0.05 \mathrm{mg} / \mathrm{mL}$ L-ascorbic acid and penicillin-streptomycin. Cultured follicles were treated with $\mathrm{FSH}(0.25 \mathrm{IU} / \mathrm{mL})$ or gC1QTNF3 protein $(3 \mu \mathrm{g} / \mathrm{mL})$ or a combination of $\mathrm{FSH}$ and gC1QTNF3, and then cultured at $37^{\circ} \mathrm{C}$ in a humidified atmosphere containing $5 \% \mathrm{CO}_{2}$ for 4 days. Medium was changed every 2 days and FSH added every day and follicular growth was monitored daily by measuring follicular diameter with Image Pro Plus 6.0.

\section{Experimental treatments on granulosa cells}

21-day-old KM female mice were injected with PMSG (5 IU/mouse) for $44 \mathrm{~h}$, and then the ovaries were collected under a laminar flow hood and placed in the cold DMEM supplemented with penicillin and streptomycin. Then, the follicles were punctured using a 27-gauge needle attached to a 1 -mL syringe to extrude granulosa cells. Granulosa cells were centrifuged at $150 \mathrm{~g}$ for $5 \mathrm{~min}$ and resuspended in the fresh DMEM/F12 medium containing 2\% FBS, insulin-transferrinselenium, streptomycin and penicillin. Their viability was assessed by counting a Trypan blue-stained preparation in a hemocytometer and cell viability ranged $80-90 \%$ were used for further study. Granulosa cells $\left(2 \times 10^{5}\right.$ cells $\left./ \mathrm{mL}\right)$ were seeded into 24-well uncoated Falcon plates and grown at $37^{\circ} \mathrm{C}$ in a humidified atmosphere containing $5 \% \mathrm{CO}_{2}$ for $2 \mathrm{~h}$, then the medium was changed to pre-warmed DMEM/F12 medium containing $0.3 \%$ BSA, insulin-transferrin-selenium, streptomycin and penicillin to remove the oocytes and starve the cells.

To determine the effect of androgen on C1qtnf3 expression, after the cells were starved overnight, graded doses of dihydrotestosterone (DHT, 0, 15, 30, 45, 90 ng/mL) were added into the medium for $6 \mathrm{~h}$ or $24 \mathrm{~h}$. At the end of culture, the cells were harvested for qPCR analysis.

Granulosa cells proliferation was measured using CellTiter 96 Aqueous One Solution Cell Proliferation Assay (MTS) kit (Promega) according to the manufacturer's protocol. Starved granulosa cells were treated with gC1QTNF3 $(3 \mu \mathrm{g} / \mathrm{mL}), \mathrm{FSH}$ $(0.25 \mathrm{IU} / \mathrm{mL})$ or a combination of gC1QTNF3 $(3 \mu \mathrm{g} / \mathrm{mL})$ and FSH $(0.25 \mathrm{IU} / \mathrm{mL})$ for 24,48 or $72 \mathrm{~h}$, and then MTS reagent $(20 \mu \mathrm{L})$ was added to $100 \mu \mathrm{L}$ of culture medium in each well. The absorbance was recorded by an ELISA reader (Biotek Instruments) at $490 \mathrm{~nm}$.

Apoptosis was measured using Caspase-Glos 3/7 Assays (Promega) after cells were stimulated with gC1QTNF3 $(3 \mu \mathrm{g} /$ $\mathrm{mL}), \mathrm{FSH}(0.25 \mathrm{IU} / \mathrm{mL})$ or a combination of gC1QTNF3 $(3 \mu \mathrm{g} /$ $\mathrm{mL})$ and $\mathrm{FSH}(0.25 \mathrm{IU} / \mathrm{mL})$ for $48 \mathrm{~h}$ in serum-free medium. All experiments were carried out with three different pools of cells collected on different occasions.

\section{Western blot analysis}

The tissues were lysed in RIPA buffer containing Halt Protease \& Phosphatase Inhibitor Cocktail (Pierce) with microelectric tissue homogenizer. After $15 \mathrm{~min}$ incubation on ice, lysates were centrifuged at $12,000 \mathrm{~g}$ for $5 \mathrm{~min}$ for removal of debris.
Total protein concentration was assessed by BCA-assay (Pierce), and $80 \mu \mathrm{g}$ of total protein was submitted to gel electrophoresis. Proteins were separated on a $12 \%$ polyacrylamide gel before transferring them to PVDF membranes (Millipore). After blocking in TBST (10 mM Tris (pH 7.5), $150 \mathrm{mM} \mathrm{NaCl}$ and $0.05 \%$ Tween 20) supplemented with 5\% BSA, membranes were incubated overnight at $4{ }^{\circ} \mathrm{C}$ with C1QTNF3 Ab (1:400), p-AKT (S473) Ab, (1:1000, CST, Cat. No. 13038), AKT Ab (1:1000, CST, Cat. No. 4691), p-mTOR (S2481) Ab (1:1000, CST, Cat. No. 2974), mTOR Ab (1:1000, CST, Cat. No. 2983), p-4EBP1 (T37/46) Ab (1:1000, CST, Cat. No. 2855), p-p70S6K (S371) Ab (1:1000, CST, Cat. No.9208), CASP3 Ab (1:1000, CST, Cat. No. 9662) or CCND2 Ab (1:200, Santa Cruz, Cat. No. sc-181). After incubation with the primary antibodies, membranes were washed three times with TBST and then incubated for $1 \mathrm{~h}$ with HRP labeled goat anti-rabbit secondary IgG (1:2000, Sigma-Aldrich, Cat. No. A0545) at room temperature. Then, the membrane was washed three times before detection with the SuperSignal West Femto Maximum Sensitivity Substrate (Thermo Fisher Scientific). After visualization of the chemiluminescent signal with GeneGenius bioimaging system (Syngene, Cambridge, UK), PVDF membrane was stripped of bound antibodies with Pierce striping buffer and incubated with $\beta$-Tubulin Ab (1:1000, Novus, Cat. No. NB600-936) or GAPDH Ab (1:1000, Sigma-Aldrich) for normalization.

\section{Ovarian intrabursal injection}

Twenty-one-day old mice were lightly anesthetized with pentobarbital sodium, and then injected with 10 or $100 \mathrm{ng}$ of C1QTNF3 Ab (Abcam, Cat. No. ab36870) in $5 \mu \mathrm{L}$ saline through the fat pad into ovarian bursa via a 30-gauge needle (BD). The contralateral ovary was injected with the same volume and concentration of normal goat IgG (negative control). An additional control was designed in which the contralateral ovary was injected with a mixture of $10 \mathrm{ng}$ C1QTNF3 Ab and $20 \mathrm{ng}$ gC1QTNF3 protein. After injection, ovaries were replaced into the mice and the incision closed with skin adhesive. Then, the mice were injected subcutaneously with PMSG (5IU/mouse) $2 \mathrm{~h}$ later and killed at $24 \mathrm{~h}$ or $48 \mathrm{~h}$. The ovaries were separated and embedded in paraffin for serial section, hematoxylin and eosin staining and follicular counting.

\section{Statistical analysis}

Data are expressed as the mean \pm S.E.M. of at least three independent experiments. Statistical analysis was performed using ANOVA followed by the Tukey-Kramer test for comparisons of multiple groups or by Student's paired $t$-test for comparison of data derived from two groups. Values with $P<0.05$ were considered statistically significant.

\section{Results}

\section{Expression patterns of the C1qtnf3 transcript during murine follicular development}

We first performed qPCR analysis to assess the transcript abundance of C1qtnf3 in the ovaries of mice aged 3-56 days old, and the results indicated that an increased 
abundance of C1qtnf3 transcripts occurred in an agedependent manner. Compared with day 3 , the transcript abundance of C1qtnf3 was significantly different in the mice on days 10, 21 and $56(P<0.05)$. Compared with day 10 , the intraovarian expression of C1qtnf3 on days 21 and 56 was also significantly increased $(P<0.05)$. A similarly significant difference for $C 1 q$ tnf3 expression was also found between days 21 and $56(P<0.05)$.

Increased levels of the C1qtnf3 transcripts were also detected, reaching their highest levels, in preovulatory follicles of 500 600 $\mu \mathrm{m}$ in diameter (Fig. 1B). The purities of the different cell types were confirmed by RT-PCR using specific markers, namely, Gdf9 for oocytes, Fshr for granulosa cells and Cyp17a1 for theca cells. The expression levels of Gdf9 in somatic, theca and granulosa cells, of Fshr and Cyp17a1 in oocytes and of Cyp17a1 in oocytes and granulosa cells were negligible (Fig. 1C). The cell population purity and isolation system appeared appropriate for further analysis. The results revealed that C1qtnf3 transcripts were mainly expressed in the granulosa cells and oocytes and negligibly expressed in the theca cells. At the early stage of folliculogenesis (day 7), C1qtnf3 transcript levels were higher in oocytes than in somatic cells $(P<0.05)$. However, at the later stage of folliculogenesis, the C1qtnf3 transcript levels were increased in granulosa cells and higher in granulosa cells than in oocytes $(P<0.05)$ (Fig. 1C).

Treatment with PMSG increased the C1qtnf3 transcript abundance, and the observed increase in C1qtnf3 transcript abundance reached significance $36 \mathrm{~h}$ after PMSG treatment compared with the PMSG baseline at $0 \mathrm{~h}(36 \mathrm{~h}$ vs $0 \mathrm{~h}, P<0.05)$. The increase in the C1qtnf3 transcript abundance $36 \mathrm{~h}$ after PMSG was significantly different from the increases at 6,12 and $24 \mathrm{~h}$ after PMSG ( $36 \mathrm{~h}$ vs $6 \mathrm{~h}, 36 \mathrm{~h}$ vs $12 \mathrm{~h}$, and $36 \mathrm{~h}$ vs $24 \mathrm{~h}, P<0.05$ ). The maximal C1qtnf3 transcript abundance was measured at $48 \mathrm{~h}$ after PMSG and was significantly compared with the C1qtnf3 transcript abundance at $36 \mathrm{~h}$ after PMSG (48h vs $36 \mathrm{~h}, P<0.05)$. Conversely, the C1qtnf3 transcript abundance was significantly decreased in response to hCG treatment for $2 \mathrm{~h}$ compared with the PMSG treatment for $48 \mathrm{~h}$ (hCG $2 \mathrm{~h}$ vs PMSG $48 \mathrm{~h}$ (hCG $0 \mathrm{~h}), P<0.05)$. After exposure to hCG for $4 \mathrm{~h}$, the C1qtnf3 transcript abundance decreased to a baseline level that was equivalent to that of pre-PMSG stimulation (Fig. 1D).

\section{C1QTNF3 distribution in the murine ovary}

Then, the C1QTNF3 protein localization in the murine ovary was examined by immunohistochemistry with 56-day-old mice. As shown in Fig. 2, C1QTNF3 staining was strongly positive in the oocytes $(\mathrm{O})$ and granulosa cells (GCs) of growing follicles, modestly positive in luteal cells and medullary interstitial (MI) cells and slightly positive in theca cells (TCs). The C1QTNF3 positivity of the oocytes in the primordial follicles (ProFs) was not uniform, and some, but not all, oocytes were positive for C1QTNF3 (Fig. 2B), suggesting that C1QTNF3 may participate in the primordial-to-primary follicle transition. In addition, the staining signals were stronger in the granulosa cells of the large follicles, such as the later antral follicles (LAFs, Fig. 2D), than in the granulosa cells of the small follicles, such as the primary follicles (PFs, Fig. 2C) and secondary follicles (SFs, Fig. 2D). Moreover, the C1QTNF3-positive signals in the granulosa cells of the atretic follicles (AtrFs, Fig. 2A, C and E) appeared weaker than those of the healthy secondary follicles (SFs, Fig. 2A and D) and antral follicles (EAFs or LAFs, Fig. 2A and D). Moreover, C1QTNF3 positivity in the corpus luteum $(\mathrm{CL}$, Fig. $2 \mathrm{~F})$ was obviously weaker than that in the granulosa cells of later antral follicles (LAFs, Fig. 2D). No C1QTNF3 staining was detected in the negative control (Fig. 2G and $\mathrm{H}$ ).

\section{Decreased intraovarian C1QTNF3 expression in DHEA- treated mice}

Because C1QTNF3 levels are low in the sera and omental adipose tissues of women with PCOS compared to control subjects (Tan et al. 2013), we used DHEA to mimic the human PCOS-like hyperandrogen condition in the mouse model. Histological analyses revealed slightly a distorted morphology, such as the formation of follicular cysts, abundant antral follicle and small atretic follicles and a reduced number of corpus lutea in the ovaries of the DHEA-treated PCOS group, in contrast to the presence of abundant corpus lutea and large antral follicles in the vehicle control ovaries (Fig. 3A and B). We also found that the estrous cycles of DHEA-treated mice were irregular and that most of the mice persisted in the diestrous phase. These observations of aberrant folliculogenesis and irregular estrous cycles were consistent with those of previous studies regarding DHEA-induced PCOS rodent models (Motta 2010). qPCR analysis showed that the C1qtnf3 transcript abundance was reduced in the DHEA-treated whole ovaries compared with the vehicle control ovaries (DHEA vs vehicle, $P<0.05$, Fig. 3C). Meanwhile, immunoblotting with C1QTNF3 antibody (Ab) demonstrated decreased C1QTNF3 expression in the polycystic ovaries compared with the vehicle ovaries (DHEA vs vehicle, $P<0.05$, Fig. 3D).

\section{High-dose DHT decreases C1qtnf3 expression in granulosa cells in vitro}

To assess whether the reduced C1QTNF3 levels in the ovaries of the hyperandrogenic PCOS mouse model occurred in granulosa cells, granulosa cells were cultured with graded doses of the active metabolite of testosterone, namely, DHT. The C1qtnf3 transcript abundance was significantly upregulated after the challenges with $15 \mathrm{ng} /$ $\mathrm{mL}$ and $30 \mathrm{ng} / \mathrm{mL}$ DHT $(P<0.05)$; however, treatments with the high concentrations of DHT $(45 \mathrm{ng} / \mathrm{mL}$ 


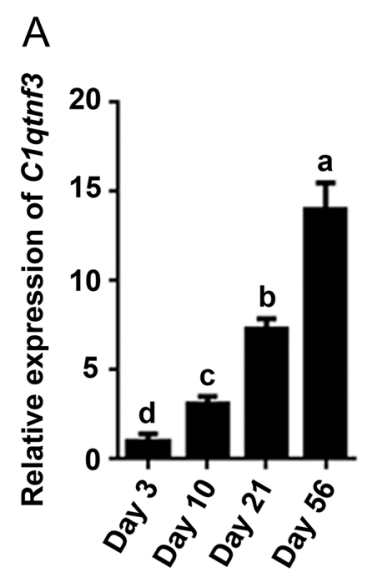

C
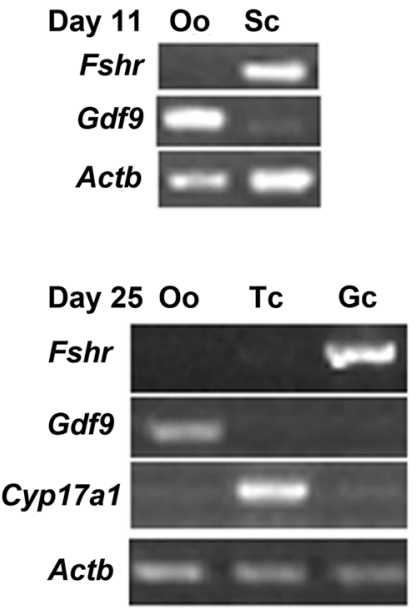

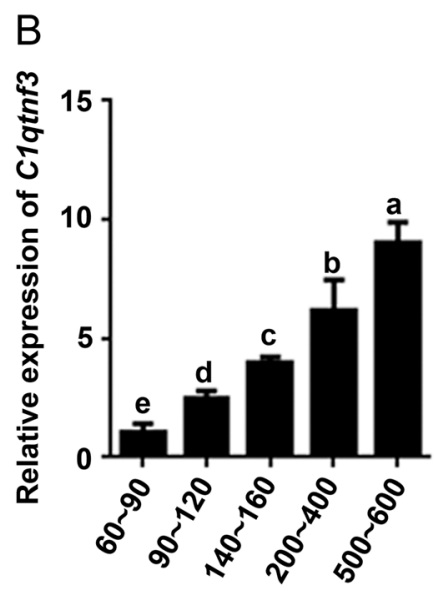

(Follicle diameter $\mu \mathrm{m})$
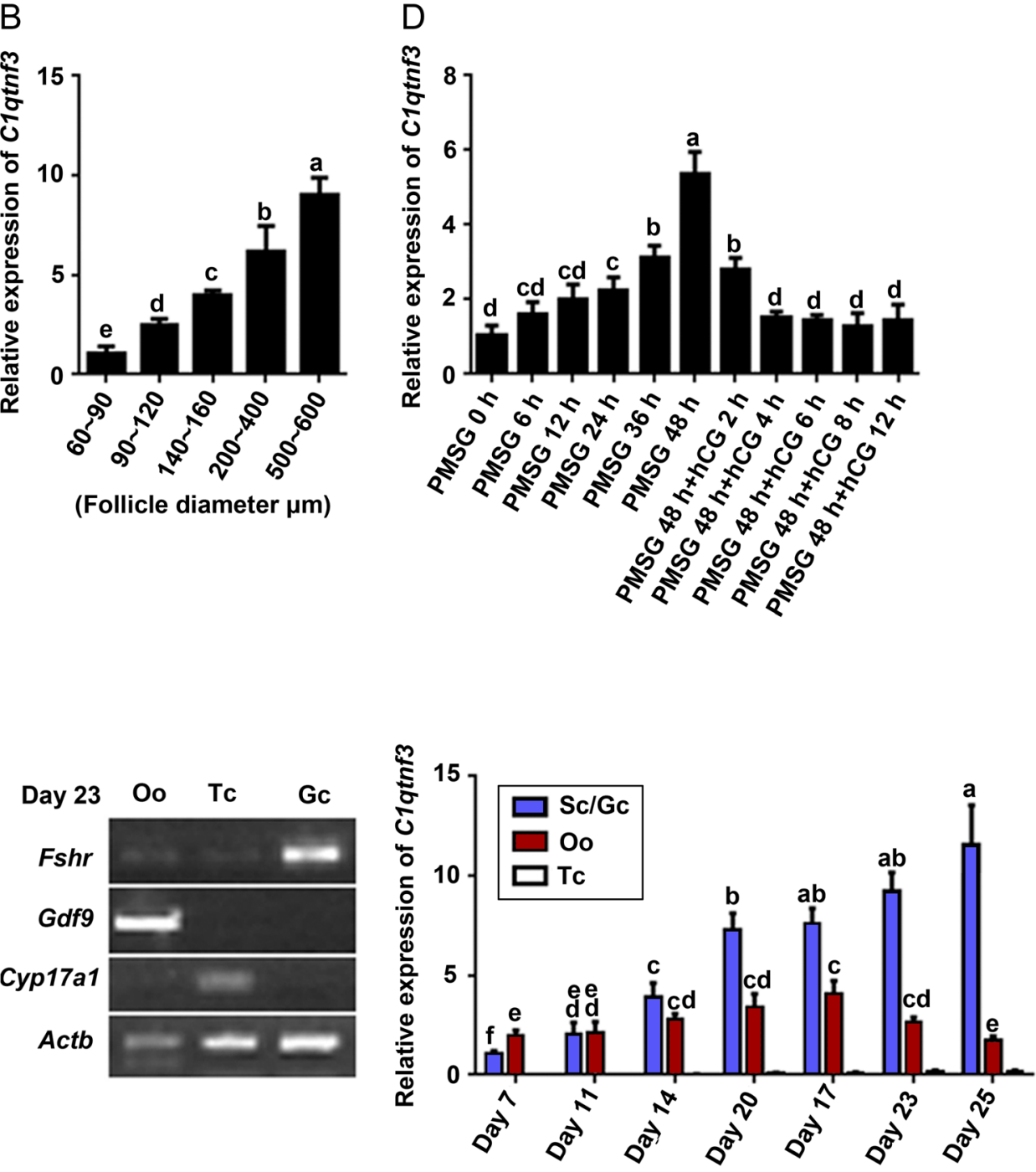

Figure 1 Expression patterns of C1qtnf3 transcript abundances during murine follicular development analyzed by qPCR. (A) Expression of C1qtnf3 transcripts in mouse ovaries of different developmental stage. Three ovaries were collected from mice aged 3, 10, 21, 56 days old. Data are indicated as a ratio to relative C1qtnf3 transcripts in the ovaries of 3-day-old mice, which was given a value of one. (B) Expression of C1qtnf3 transcripts in isolated follicles of different sizes. Follicles (3 10 follicles per sample) of different diameters were isolated from 12-dayold mice $(60 \sim 160 \mu \mathrm{m}$ in diameter), 23-day old mice (200 400 $\mu \mathrm{m}$ in diameter) and 56-day-old mice (500 600 $\mu \mathrm{m}$ in diameter) for analysis. Data are indicated as a ratio to relative C1qtnf3 transcript abundances in the follicles of $60 \sim 90 \mu \mathrm{m}$ in diameter, which was given a value of one. (C) Expression of C1qtnf3 transcripts in different ovarian cell types. Ovaries from 7-day-old and 14-day-old mice were dissected to obtain oocytes and somatic cells (Sc). In addition, granulosa cells (Gc), theca cells (Tc) and oocytes (Oo) from mice aged 14, 17, 20, 23 days and mice aged 25 days (23-day-old mice were treated with PMSG for $48 \mathrm{~h}$ ). The purities of ovarian cells were confirmed by RT-PCR using specific markers, Gdf9 for oocyte (Oo), Fshr for granulosa cells (Gc) and Cyp17a 1 for theca cells (Tc). Data were indicated as a ratio to C1qtnf3 transcript abundances in the somatic cells of 7-day-old mice, which was given a value of one. (D) Gonadotropin regulation of C1qtnf3 transcript abundances in murine ovaries. The immature 21-day-old mice were treated with PMSG (5 IU/each mouse) to induce follicle maturation, following at $48 \mathrm{~h}$ with an injection of hCG (5 IU/each mouse) to induce ovulation. In each time point, three mice were killed, and the cDNA of each mouse were synthesized separately. Data were indicated as a ratio to C1qtnf3 expression level in the ovaries of 21-day-old immature mice without PMSG treatment, which was given a value of one. Actb was an internal control. Bars (mean \pm S.E.M.) with different lowercase letters are significantly different $(P<0.05)$.

and $90 \mathrm{ng} / \mathrm{mL}$ ) significantly decreased the C1qtnf3 transcript abundance $(P<0.05)$ (Fig. 3E). These results demonstrated that low doses of androgen stimulated C1qtnf3 expression in granulosa cells; however, high doses of androgen inhibited C1qtnf3 expression.

\section{C1QTNF3 promotes FSH-induced follicular development}

FSH treatment for 4 days increased the weights of ovarian explants from 10-day-old mice, as expected. The ovaries that were incubated in $1 \mu \mathrm{g} / \mathrm{mL}$ gC1QTNF3-containing 


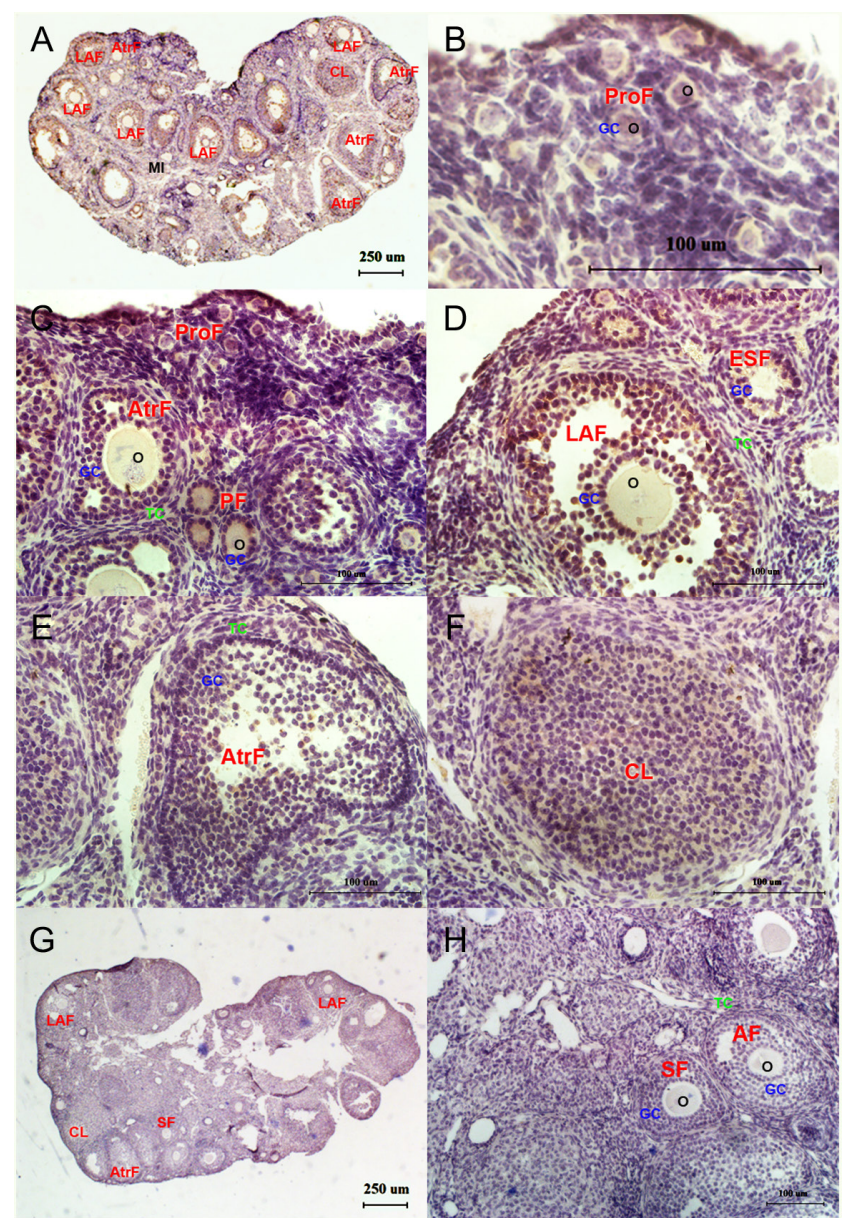

Figure 2 Localization of C1QTNF3 protein in the ovary of 56-day-old mice by immunohistochemistry. Representative sections showed localization of $\mathrm{C} 1 \mathrm{QTNF} 3$ protein in the whole ovary $(\mathrm{A})$ and in primordial (ProFs, B, C), primary (PFs, C), secondary (SFs, D), atretic follicles (AtrFs, C and E), later antral (LAFs, D) and corpus luteum $(\mathrm{CL}, \mathrm{F})$. C1QTNF3 staining was strongly positive in the oocytes $(\mathrm{O})$ and granulosa cells (GCs) of growing follicles, modestly positive in luteal cells and medullary interstitial (MI) cells, and slightly positive in theca cells (TCs). The C1QTNF3-positive signals in the granulosa cells of the atretic follicles appeared weaker than those of the healthy secondary follicles and antral follicles. No staining of C1QTNF3 positive signal was detected in the negative control $(\mathrm{G}$ and $\mathrm{H})$. Bar scale labeled on A and G was $250 \mu \mathrm{m}$, others was $100 \mu \mathrm{m}$.

medium for 4 days showed similar weights to those incubated in gC1QTNF3-free medium. Treatment with $3 \mu \mathrm{g} / \mathrm{mL}$ gC1QTNF3 slightly increased the ovarian weight, but the increase was not significantly different from that of the control or the $1 \mu \mathrm{g} / \mathrm{mL}$ gC1QTNF3 treatment $(3 \mu \mathrm{g} /$ $\mathrm{mL}$ vs control, $P=0.23 ; 3 \mu \mathrm{g} / \mathrm{mL}$ vs $1 \mu \mathrm{g} / \mathrm{mL}, P=0.18)$. The $10 \mu \mathrm{g} / \mathrm{mL}$ gC1QTNF3 treatment had a higher tendency toward increasing the ovarian weight than the $3 \mu \mathrm{g} / \mathrm{mL}$ gC1QTNF3 treatment, but the difference did not reach statistical significance $(10 \mu \mathrm{g} / \mathrm{mL}$ vs $3 \mu \mathrm{g} / \mathrm{mL}$, $P=0.08)$. However, the combination treatment with $3 \mu \mathrm{g} /$ $\mathrm{mL}$ gC1QTNF3 and $\mathrm{FSH}(0.25 \mathrm{IU} / \mathrm{mL})$ led to significant weight gain ( $\mathrm{FSH}+\mathrm{C} 1 \mathrm{QTNF3}$ vs $\mathrm{FSH}, P<0.05)$. These
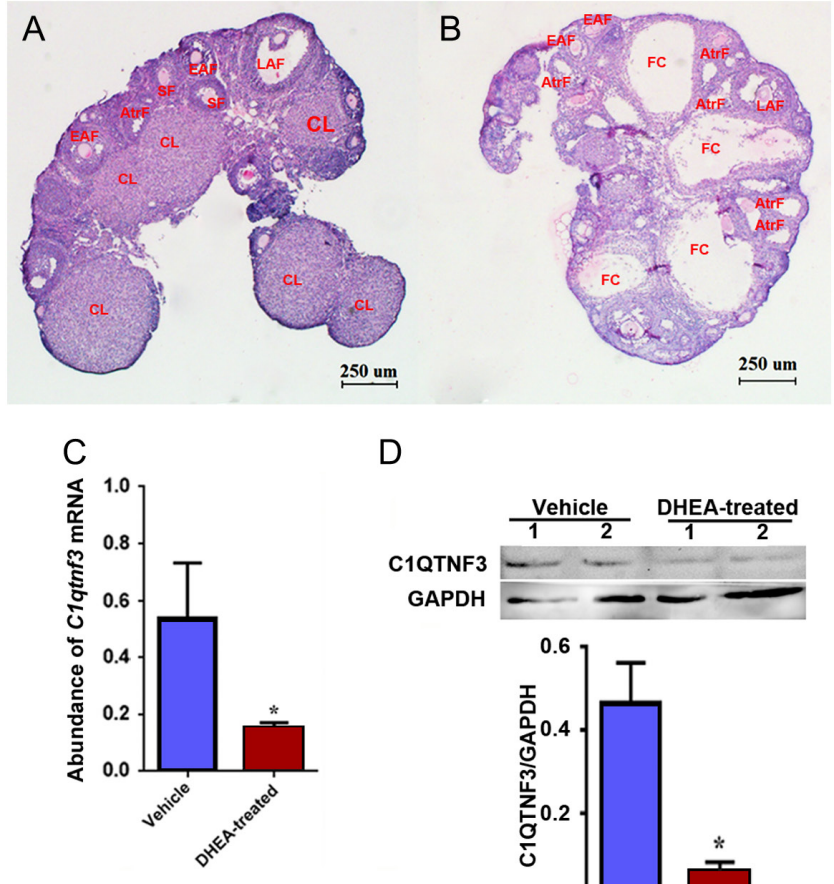

D
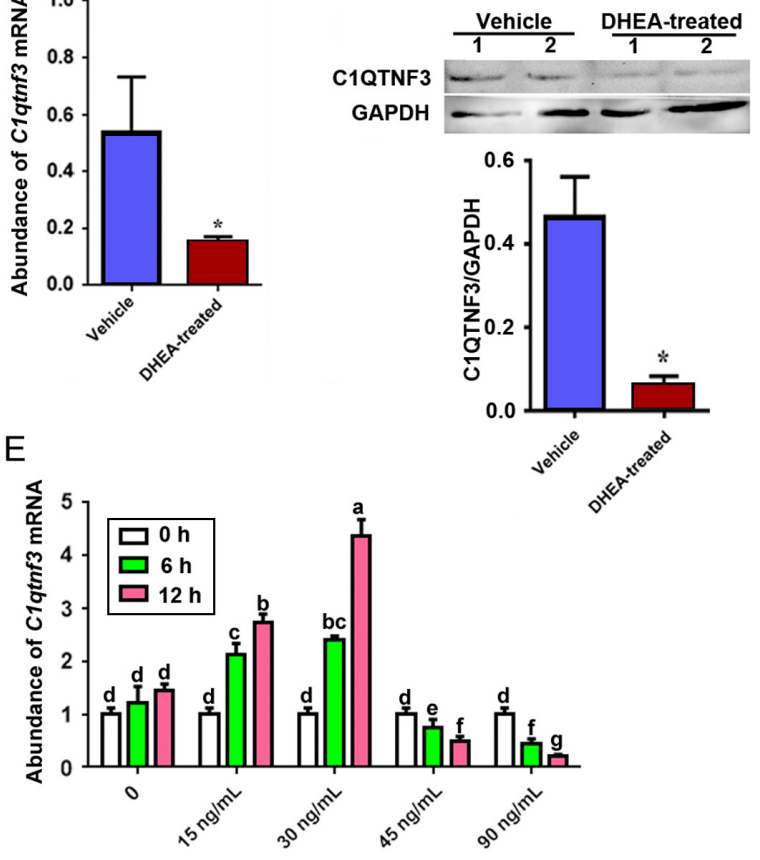

Figure 3 Decreased expression of C1QTNF3 in the polycystic ovary of DHEA-treated mice and DHT-challenged granulosa cells. (A and B) Hematoxylin and eosin staining was performed in the ovarian tissues from DHEA-treated PCOS mice (B) and vehicle control (A). The distorted morphology such as the formation of follicular cysts (FCs), abundant early antral follicles (EAFs) and atretic follicles (AtrFs), and reduced number of corpus luteum $(\mathrm{CL})$ was displayed in ovaries of DHEA-treated PCOS group. The ovary of vehicle control was healthy with a mount of corpus leteum $(\mathrm{CL})$ and growing follicles in each stage, such as primary follicles (PFs), secondary follicles (SFs), early antral follicles (EAFs), later antral follicles (LAFs). (C) The C1qtnf3 transcript abundances in the polycystic ovaries of DHEAtreated mice and vehicle control analyzed by qPCR, Actb were used as the reference gene. Data are presented as mean \pm S.E.M. from 8 mice in each group. ${ }^{*} P<0.05$. (D) Western blot analysis of C1QTNF3 protein in DHEA-treated and vehicle ovaries. The representative image of 2 mice from vehicle and 2 mice form DHEA-treated group was shown. Data are expressed as mean \pm S.E.M. ${ }^{*} P<0.05, n=8$. (E) DHT downregulated the C1qtnf3 transcript abundance in cultured granulosa cells. qPCR was used to measure the C1qtnf3 transcript abundances in granulosa cells after stimulation with different dose of $\mathrm{DHT}$ for $6 \mathrm{~h}$ or $12 \mathrm{~h}$. Actb was used as the reference gene. The relative C1qtnf3 transcript abundances in different treatment were indicated as ratios to negative control at $0 \mathrm{~h}$. Data are represented mean \pm S.E.M. of three independent cultures. Bars with different lowercase letters are significantly different $(P<0.05)$. 
results demonstrated that C1QTNF3 accelerated FSHinduced ovarian weight gain. Due to the promoting effect of FSH on follicular development and the augmenting effect of C1QTNF3 on FSH-induced ovarian growth, we hypothesized that C1QTNF3 was more effective toward the weight gains of larger ovarian tissues. Thus, we used ovarian explants from 12-day-old mice to test this hypothesis. However, no significant difference was evident for the C1QTNF3 treatment between the day 12 ovaries and day 10 ovaries, though C1QTNF3 promoted more ovarian weight gain in day 12 ovaries $(124.44 \%$ of control) than in day 10 ovaries $(118.08 \%$ of control). We also tested the fC1QTNF3 protein effect on the weight gain of the ovarian explants and observed a similar effect to that of the globular domain, namely, gC1QTNF3 (data not shown), so gC1QTNF3 was used in subsequent experiments. Histological analyses showed obvious increases in later preantral follicles in the ovarian explants from 12-day-old mice after these explants were incubated in medium containing both FSH and gC1QTNF3 (Fig. 4C). A detailed counting of follicles of different sizes showed a similar phenotype. gC1QTNF3 treatment had no significant effect on follicular development. The combination treatment with FSH and gC1QTNF3 increased $(126.43 \pm 4.50 \%)$ the proportion of later secondary follicles compared to the treatment with $\mathrm{FSH}$ alone $(P<0.05)$, and this increase was accompanied by a decrease in the proportion of primordial follicles (Fig. 4D).

We further investigated the effect of gC1QTNF3 on follicular development with an in vitro preantral follicles culture system. As shown in Fig. 4F, gC1QTNF3 treatment increased the sizes of the small preantral follicles (90 120 $\mu \mathrm{m}$ in diameter), and the observed increases were only significant relative to the control after gC1QTNF3 treatment for 4 days $(P<0.05)$. The increases in follicular size reached significance on day 3 after FSH stimulation compared with FSH-free medium incubation. Meanwhile, the combined treatment comprising gC1QTNF3 and FSH led to a great increase in follicular growth in the day 4 culture compared with the FSH treatment (gC1QTNF+FSH vs FSH, day $3, P<0.05)$. The same phenomenon was also observed for the large preantral follicle $(130 \sim 150 \mu \mathrm{m}$ in diameter) culture (Fig. 4F). However, in the large preantral follicle group, gC1QTNF3 alone led to a significant increase in the follicular diameter from day 3 to day 4 of culturing, and this effect was not observed in the small preantral follicle group, suggesting that gC1QTNF3 actions on preantral follicular development were more prominent in large follicles.

\section{C1QTNF3 effects on ovarian growth are associated with granulosa cell proliferation and apoptosis}

The relatively highly levels of C1QTNF3 in the granulosa cells of growing follicles and the ability of C1QTNF3 to induce ovarian growth motivated us to determine
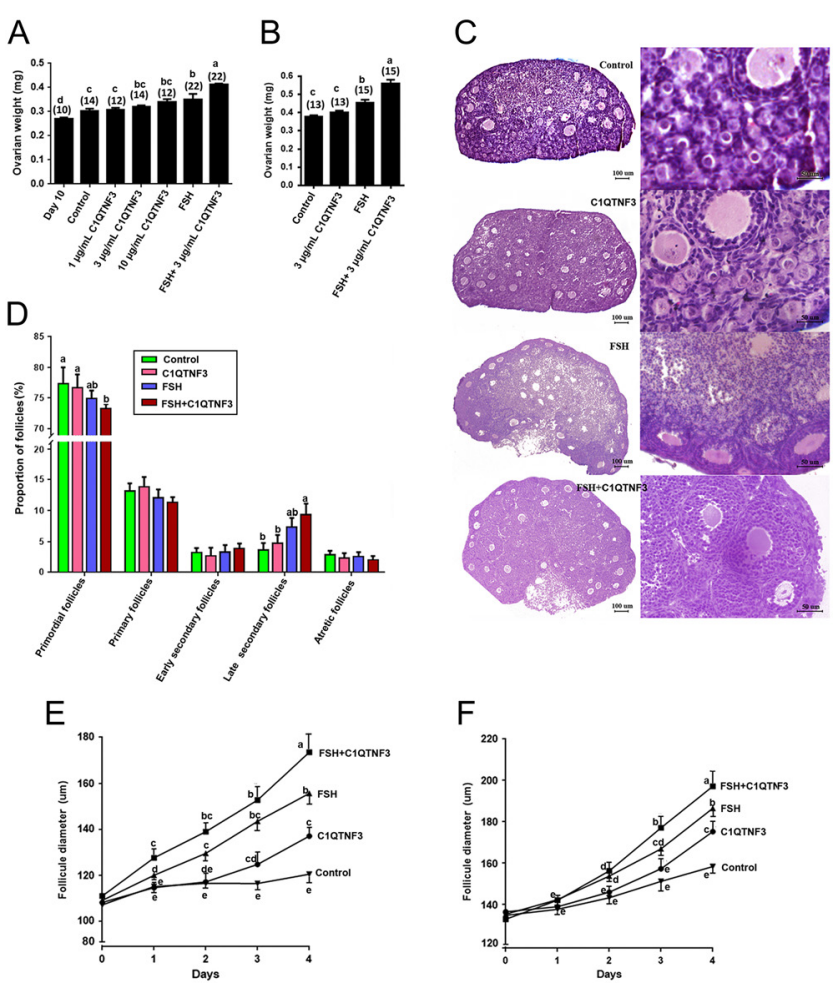

Figure 4 Recombinant C1QTNF3 protein promotes growths of cultured ovarian explants and isolated preantral follicles. (A) Ovarian explants of 10-day old mice were treated with gC1QTNF3 and/or $\mathrm{FSH}$, and ovarian weight was determined 4 days later. Paired ovaries were treated with control and $3 \mu \mathrm{g} / \mathrm{mL}$ gC1QTNF3, or $1 \mu \mathrm{g} / \mathrm{mL}$ and $10 \mu \mathrm{g} / \mathrm{mL}$ gC1QTNF3, or $3 \mu \mathrm{g} / \mathrm{mL}$ gC1QTNF3 combined with $0.25 \mathrm{IU} /$ $\mathrm{mL} \mathrm{FSH}$ and $0.25 \mathrm{IU} / \mathrm{mL}$ FSH. FSH was added every day, and the medium containing different dose of gC1QTNF3 were changed every 2 day. Numbers of ovaries used are shown in parentheses. (B) Ovarian explants of 12-day old mice were treated with FSH (0.25 IU/ $\mathrm{mL})$ and/or gC1QTNF3 $(3 \mu \mathrm{g} / \mathrm{mL})$ for 4 days, and ovarian weight was measured. (C) Ovarian explants of 12-day old mice were treated with C1QTNF3 $(3 \mu \mathrm{g} / \mathrm{mL})$ and /or FSH $(0.25 \mathrm{IU} / \mathrm{mL})$, ovarian histology was analyzed by HE staining. (D) Ovarian explants were treated with gC1QTNF3 $(3 \mu \mathrm{g} / \mathrm{mL})$ and/or FSH $(0.25 \mathrm{IU} / \mathrm{mL})$, follicle proportion was analyzed by continuous sections follicles counting. (E and F) Preantral follicles in diameter $90 \sim 120 \mu \mathrm{m}$ (E) and in diameter $125 \sim 150 \mu \mathrm{m}(\mathrm{F})$ isolated from 12 14-day old mice and treated with gC1QTNF3 $(3 \mu \mathrm{g} / \mathrm{mL})$ and/or FSH $(0.25 \mathrm{IU} / \mathrm{mL})$ for 4 days, and follicle diameters were measured daily ( $n=20 \sim 38$ follicles). Data are expressed as mean \pm S.E.M. Different lowercase letters are significantly different $(P<0.05)$.

C1QTNF3 effects on granulosa cell health, such as proliferation and apoptosis. As expected, FSH increased cell cycle marker CCND2 expression in cultured ovarian explants at $48 \mathrm{~h}(P<0.05)$ and $96 \mathrm{~h}(P<0.01)$. Like the $\mathrm{FSH}$ treatment, the gC1QTNF3 treatment and the combination gC1QTNF3 and FSH treatment upregulated CCND2 expression $(P<0.05)$. However, although the CCND2 level was increased by the FSH plus C1QTNF3 treatment, C1QTNF3 had no significant effect on FSHinduced CCND2 expression (Fig. 5A). To further confirm whether C1QTNF3 played a role in granulosa cell 
A
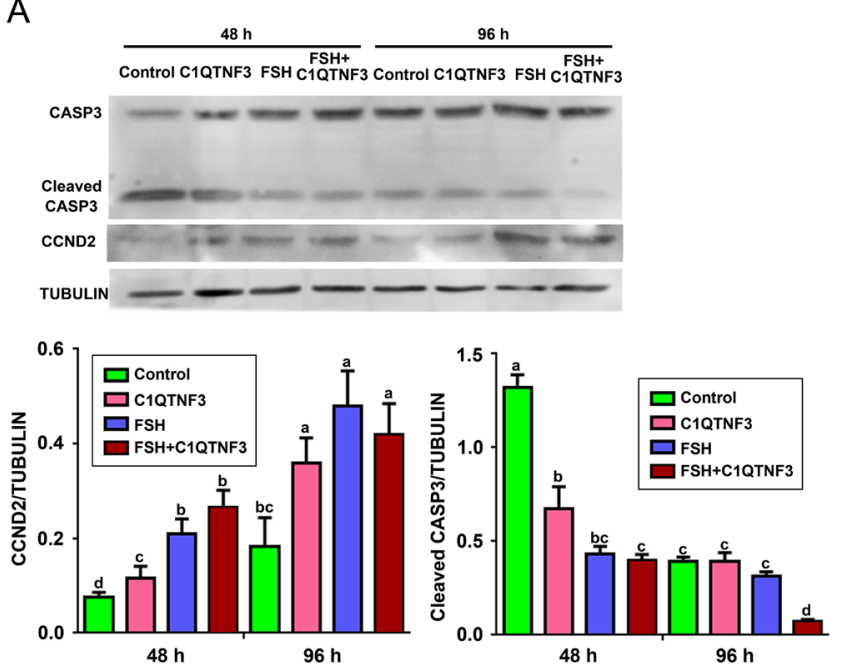

B

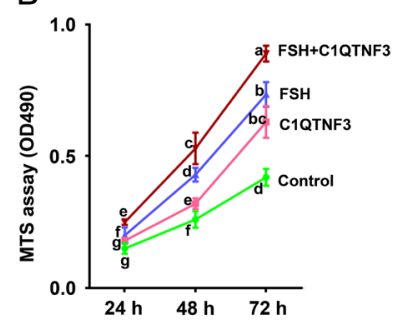

C

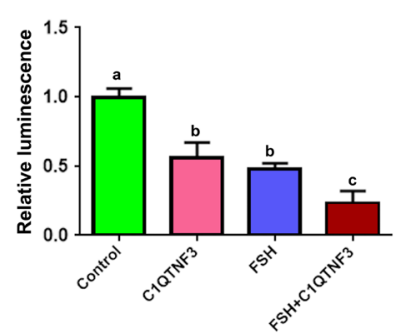

Figure 5 The effect of C1QTNF3 on follicular growth is associated with proliferation and apoptosis of granulosa cells. (A) Western blot analyzed the effect of C1QTNF3 protein on expression of CCND2 and activation of CASP3. The ovarian explants of 12-day old mice were treated with gC1QTNF3 $(3 \mu \mathrm{g} / \mathrm{mL}), \mathrm{FSH}(0.25 \mathrm{IU} / \mathrm{mL})$ or FSH plus gC1QTNF3 $(3 \mu \mathrm{g} / \mathrm{mL})$ for $48 \mathrm{~h}$ or $96 \mathrm{~h}$, then the ovaries were used for Western blot analysis. A blot of one replicate is shown, and the quantitation of CCND2 and cleaved CASP3 is normalized with TUBULIN and shown in statistical charts. (B) Effect of C1QTNF3 on proliferation in cultured granulosa cells. Granulosa cells were cultured with gC1QTNF3 $(3 \mu \mathrm{g} / \mathrm{mL})$, FSH $(0.25 \mathrm{IU} / \mathrm{mL})$ or FSH plus gC1QTNF3 $(3 \mu \mathrm{g} / \mathrm{mL})$ for 24,48 or $72 \mathrm{~h}$, then the viability of cells were measured. (C) Effect of C1QTNF3 on apoptosis in cultured granulosa cells. Granulosa cells were cultured in the serum free medium, and treated with gC1QTNF3 $(3 \mu \mathrm{g} / \mathrm{mL}), \mathrm{FSH}(0.25 \mathrm{IU} / \mathrm{mL})$ or FSH plus gC1QTNF3 $(3 \mu \mathrm{g} / \mathrm{mL})$ for $24 \mathrm{~h}$, then the cell luminescence was measured. The enzymatic activities measured in each treatment were compared with the activities in the cells cultured in serum-free conditions (control). In each assay, data are expressed as mean \pm S.E.M. of three independent replicates, and different lowercase letters are significantly different $(P<0.05)$.

proliferation, MTS assays were performed after granulosa cell isolation and culturing in vitro. An increase in the absorbance value at $490 \mathrm{~nm}$ was significant at $48 \mathrm{~h}$ after the FSH challenge and at $96 \mathrm{~h}$ after C1QTNF3 stimulation $(P<0.01)$. C1QTNF3 enhanced the effect of $\mathrm{FSH}$ when granulosa cells were challenged with both FSH and gC1QTNF3. Furthermore, the absorbance value at $490 \mathrm{~nm}$ was increased significantly at $96 \mathrm{~h}$ after the gC1QTNF3 and FSH combination treatment compared with FSH stimulation alone at 96h $(P<0.05)$ (Fig. 5B).
Cleaved CASP3 expression decreased significantly at $48 \mathrm{~h}$ after the gC1QTNF3 challenge compared to cleaved CASP3 expression in the cultured ovarian explants that were not exposed to exogenous gonadotropin or proteins $(P<0.05)$. Meanwhile, total CASP3 expression was relatively stable among the different treatment groups. No significant difference was evident between the FSH and gC1QTNF treatments, suggesting that C1QTNF3and FSH-mediated protection against apoptosis occurred in a similar manner. After the explants were cultured for $96 \mathrm{~h}$, the medium containing both FSH and gC1QTNF3, but not the medium containing FSH or C1QTNF3 alone, significantly reduced CASP3 activation $(P<0.01)$ (Fig. 5A). To further confirm that the C1QTNF3-mediated inactivation of CASP3 occurred through granulosa cells, cells were challenged with gC1QTNF3 and/or FSH in serum-free medium, and CASP3/7 activity was measured and compared with the CASP3/7 activities of the cells cultured in medium without serum, FSH or C1QTNF3 (control). An approximately 0.5 -fold decrease in cell luminescence was evident in the C1QTNF3-treated cells compared with the cells cultured in serum-free medium, indicating that C1QTNF3 had an inhibitory effect on serum deprivation-induced granulosa cell apoptosis, and the effect of C1QTNF3 was as potent as that of FSH. Meanwhile, after cells were stimulated with both FSH and gC1QTNF3, luminescence was remarkably decreased to a very low level (0.23-fold that of the control), even compared with that of the FSH treatment $(P<0.01)$ (Fig. 5C). These results showed that C1QTNF3 had a similar effect to that of FSH in terms of inhibiting granulosa cell apoptosis; moreover, C1QTNF3 was strongly able to augment the anti-apoptosis effect of $\mathrm{FSH}$.

\section{The stimulatory effect of C1QTNF3 on ovarian growth was associated with AKT and mTOR phosphorylation}

The addition of gC1QTNF3 to the medium for the ovarian explant cultures caused increases in p-AKT/AKT and $\mathrm{p}-\mathrm{mTOR} / \mathrm{mTOR}$ at $30 \mathrm{~min}$ and $60 \mathrm{~min}$, as did the addition of FSH. When gC1QTNF3 and FSH were both added to the medium, the p-AKT/AKT and p-mTOR/ mTOR ratios were remarkably enhanced compared FSH or gC1QTNF3 alone, suggesting that C1QTNF3 potently increased $\mathrm{FSH}$-induced AKT and mTOR phosphorylation (Fig. 6). mTOR phosphorylation of target molecules, namely, p70S6 kinase (p70S6K) and eukaryotic translation initiation factor $4 \mathrm{E}$-binding protein 1 (4EBP1), is a downstream event of mTOR signaling. To further examine the mechanism of action of C1QTNF3, we assessed p7056K and 4EBP1 activation. When the ovarian explants were incubated with gC1QTNF3 or FSH alone for $30 \mathrm{~min}, \mathrm{p} 70 \mathrm{~S} 6 \mathrm{~K}$ and $4 \mathrm{EBP} 1$ phosphorylation increased. p70S6K activation was sustainably increased at $60 \mathrm{~min}$, though the activating effect was reduced compared with that at $30 \mathrm{~min}$; however, 4EBP1 

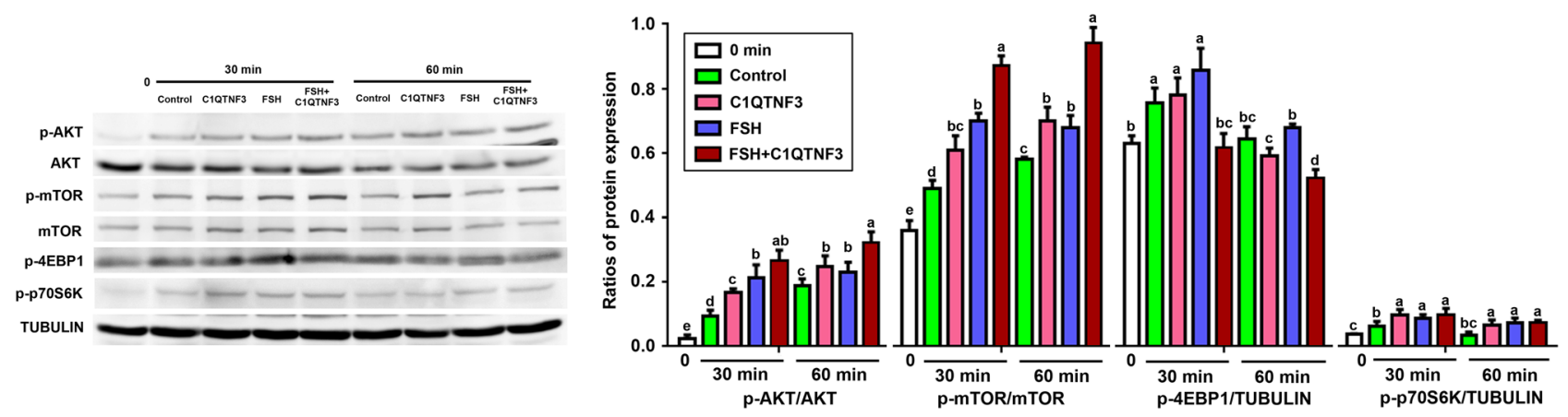

Figure 6 The effect of C1QTNF3 on follicle growth is associated with activation of AKT and mTOR. Western blot analyzed the effect of C1QTNF3 protein on phosphorylation of AKT, mTOR, p70S6K and 4EBP1. Ovarian explants of 12-day mice were treated with gC1QTNF3 (3 $\mu$ g/ $\mathrm{mL})$, FSH $(0.25 \mathrm{IU} / \mathrm{mL})$ or FSH plus gC1QTNF3 $(3 \mu \mathrm{g} / \mathrm{mL})$ for 30 and $60 \mathrm{~min}$, then the cultured ovaries were collected for detecting the expression of phosphorylation of targeted proteins, which are used as quantitative analysis and shown in statistical charts. Data are expressed as mean \pm S.E.M. of three independent replicates, and different lowercase letters are significantly different $(P<0.05)$.

phosphorylation was reduced to baseline. The effects of the gC1QTNF3 and FSH combination treatment on the activation of p70S6K and 4EBP1 phosphorylation were not consistent with the effects of this treatment on the activation of AKT and mTOR. No obvious differences were evident between the combination treatment and individual treatments in terms of p70S6K activation at $30 \mathrm{~min}$ or $60 \mathrm{~min}$. This result suggested that gC1QTNF3 did not act synergistically with FSH to activate p70S6K. Unlike p70S6K activation, the gC1QTNF3 and FSH combination treatment significantly attenuated 4EBP1 phosphorylation at $60 \mathrm{~min}(P<0.01)$.

\section{Delayed follicular development with the intrabursal administration of C1QTNF3 antibody}

To further evaluate the effect of C1QTNF3 on follicular growth in vivo, a C1QTNF3 Ab that was produced with a 16-amino-acid peptide derived from the central region of C1QTNF3 was administered via intrabursal injection. The average weight of the ovary at $24 \mathrm{~h}$ after PMSG stimulation was not changed by injections with either $10 \mathrm{ng}$ or $100 \mathrm{ng}$ of C1QTNF3 Ab; however, both concentrations decreased the weight of the ovary at $48 \mathrm{~h}$ $(P<0.05)$. Furthermore, the inhibitory effect on ovarian weight gain was more obvious in the $100 \mathrm{ng}$ C1QTNF3 $\mathrm{Ab}$ treatment group than in the $10 \mathrm{ng} \mathrm{Ab}$ treatment group at $48 \mathrm{~h}$ after PMSG stimulation (Fig. 7A). Histological morphology and follicular counting analyses showed that the C1QTNF3 Ab injection remarkably decreased the average diameter of the antral follicles (Fig. 7B). No significant differences were evident between the low-dose and high-dose C1QTNF3 groups in terms of changes in ovarian weight or follicular morphology. To confirm the effect of the C1QTNF3 Ab on follicular development, we pre-incubated C1QTNF3 Ab with gC1QTNF3 protein and then injected the mixture into the ovarian bursa. After the $A b$ pre-absorption with $20 \mathrm{ng}$ of gC1QTNF3 protein, the ovarian weight was obviously increased compared to the Ab treatment alone, and weight gain was accompanied by antral expansion (Fig. 7). These results demonstrated that the effect of the C1QTNF3 Ab on delaying antral follicle development was neutralized by pre-absorption with excess gC1QTNF3 protein.

\section{Discussion}

Follicular development is regulated by endocrine signals but is also modulated by a number of locally produced intraovarian factors whose actions are both paracrine and autocrine (Hsueh et al. 2015). In this study, we showed that C1QTNF3, a novel adipokine with modulating effects on metabolism, inflammation and the cardiovascular system, functioned as an intraovarian factor that is involved in follicular development. Although C1qtnf3 mRNA has previously been detected in human ovarian tissues (Schaffler \& Buechler 2012), we are the first to define the intraovarian expression patterns of C1qtnf3 with respect to age, follicle size and the follicular compartment and to reveal the effects of PMSG and hCG on C1qtnf3 transcript abundance in mice. Moreover, we performed immunochemistry to demonstrate the localization of C1QTNF3 in different ovarian cell types. The C1qtnf3 expression pattern is different from that of its paralog, adiponectin, which is mainly expressed in theca-interstitial cells, the corpus luteum, oocytes and less abundantly in granulosa cells (Chabrolle et al. 2007). In contrast to adiponectin, C1QTNF3 was mainly detected in granulosa cells and oocytes and less abundantly expressed in the corpus luteum and theca cells. Moreover, C1QTNF3 and adiponectin showed different responses to gonadotropin in the immature ovary. hCG is an LH-like hormone, whereas PMSG is known to mimic FSH effects. Adiponectin expression was unchanged after PMSG treatment for $48 \mathrm{~h}$ but increased in response to hCG treatment (Chabrolle et al. 2007). The C1qtnf3 transcript abundance was 
A

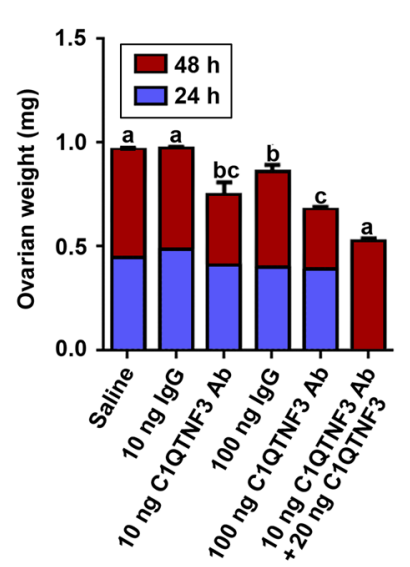

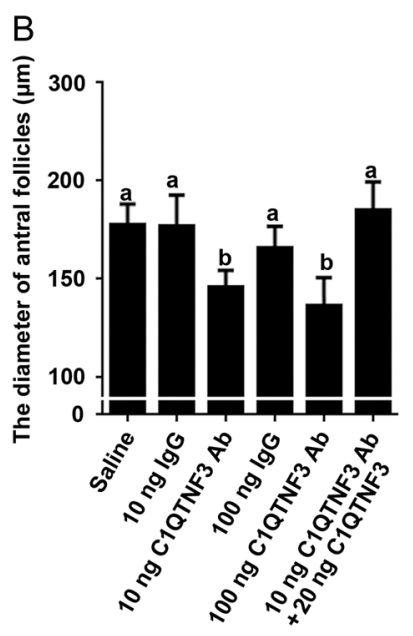

Figure 7 Neutralization of C1QTNF3 delayed the gonadotropinstimulated antral follicle growth. (A) 21-day old female mice were anesthetized and the ovaries were exteriorized through an incision made in the dorsal lumbar region. Mice then received 0, 10, or $100 \mathrm{ng}$ of C1QTNF3 Ab in $10 \mu \mathrm{L}$ of saline under the bursa of one ovary (C1QTNF3 Ab ovary). The contralateral ovary was injected with the same volume and concentration of normal goat IgG (control ovary). An additional treatment was designed in which ovary was injected with $10 \mathrm{ng}$ C1QTNF3 Ab previously adsorbed with the $20 \mathrm{ng}$ gC1QTNF3 protein and the contralateral ovary was injected with 10 ng C1QTNF3 Ab. After injection, ovaries were replaced and the incision closed with skin adhesive. Mice then were injected subcutaneously with $5 \mathrm{IU} /$ mouse PMSG $2 \mathrm{~h}$ later. After injection with PMSG $24 \mathrm{~h}$ and $48 \mathrm{~h}$, ovarian weight was determined. Data are expressed as mean \pm S.E.M. of 10 mice, and different lowercase letters are significantly different $(P<0.05)$. (B) The average diameter of antral follicles in each group. After injection with PMSG for $48 \mathrm{~h}$, ovaries were fixed and embedded in paraffin, and serially sectioned for staining with hematoxylin and eosin. The diameter of maximal section with oocyte of each antral follicle was measured by Image Pro Plus 6.0. Data are indicated as mean \pm S.E.M. of 5 mice, and different lowercase letters are significantly different $(P<0.05)$.

upregulated by FSH and downregulated by hCG, which was consistent with the higher C1QTNF3 levels in the granulosa cells of the large follicles and with the lower C1QTNF3 levels in the corpus luteum. The different expression patterns and localizations of C1QTNF3 and adiponectin suggested that they may play different roles in ovarian growth. Presumably, adiponectin participates in granulosa cell steroidogenesis by signaling through its receptors (AdipoR1 and AdipoR2), which are expressed in granulosa cells (Tabandeh et al. 2010). The putative receptor of C1QTNF3, LAMP-1, has been detected in oocytes and granulosa cells (Escobar et al. 2008, HulasStasiak et al. 2016, Li et al. 2016), which suggests that C1QTNF3 may act together with LAMP-1 to carry out C1QTNF3-associated biological functions, such as promoting proliferation and reducing apoptosis in granulosa cells, as shown in our studies.

The promoting effect of C1QTNF3 on follicular development was verified with ovarian explant culture assays, in vitro preantral follicle cultures and intrabursal injections. The addition of C1QTNF3 to cultured ovarian explants increased the expression of CCND2, a cell cycle marker that is mainly localized in granulosa cells and is an important factor in the regulation of granulosa cell proliferation during normal folliculogenesis (Robker \& Richards 1998). The enhancement effect of C1QTNF3 on proliferation has been reported in other cell types, such as undifferentiated C2C12 myoblasts, prostate cells, smooth muscle cells, endothelial cells, chondrogenic precursors and chondrocytes (Maeda et al. 2006, Akiyama et al. 2007, Maeda \& Wakisaka 2010, Hou et al. 2014, 2015, Otani et al. 2015). MTS assays were performed to further confirm the effect of C1QTNF3 on granulosa cell proliferation. Granulosa cells proliferate until the follicle either reaches a large, multilaminar preovulatory state or dies via a regulated apoptotic process, termed follicle atresia. Anti-apoptosis has been reported as a main function of C1QTNF3 for sustaining the survival of multiple cell types, such as mesenchymal stem cells and cardiomyocytes (Yi et al. 2012, Hou et al. 2014). The effect of C1QTNF3 against granulosa cell apoptosis was demonstrated by a reduction in activated CASP3 in cultured ovarian explants and granulosa cells and by a reduction in C1QTNF3 expression in atretic follicles. Although C1QTNF3 possessed the ability to induce follicle growth by accelerating granulosa cell proliferation and to prevent follicular atresia by inhibiting granulosa cell apoptosis in a similar manner to $\mathrm{FSH}$, the main endocrine regulator of ovarian follicle growth and development (Kumar et al. 1997), the effects of C1QTNF3 on ovarian weight gain and follicular diameter increases were not as strong as those of $\mathrm{FSH}$. However, the addition of C1QTNF3 significantly augmented the effect of $\mathrm{FSH}$ on follicular growth. We have deduced that C1QTNF3 may carry out this augmenting effect by increasing FSH sensitivity and that C1QTNF3 may be involved in follicle development. The enhancement activity of C1QTNF3 on FSH-induced CASP3 activation confirmed this hypothesis. The sensitizing effect of C1QTNF3 has also been shown in terms of the $\mathrm{Ca}^{2+}$ sensitivity of cardiomyocytes (Zhang et al. 2017). In fact, many intraovarian molecules that are secreted by granulosa cells, such as estradiol (Messinis 2006), anti-Müllerian hormone (Durlinger et al. 2001), and wingless-type mouse mammary tumor virus integration site 5a (Abedini et al. 2015), have been found to regulate FSH responsiveness. C1QTNF3 may be a novel intraovarian factor that modulates the $\mathrm{FSH}$ responsiveness of follicles. Meanwhile, C1qtnf3 expression was upregulated by PMSG, and C1QTNF3 positivity was highly localized to the granulosa cells of antral follicles, whose growth is mainly regulated by FSH. Both C1QTNF3 and FSH were able to augment the effects of the other, creating a positive feedback loop.

Various intracellular C1QTNF3-activated pathways, such as the TGF $\beta / S M A D$ pathway in hepatic stellate cell activation (Cheng et al. 2017), PKC pathway in 
stimulating the proliferation and anti-apoptosis of prostate cells (Hou et al. 2015), AMPK pathway in inhibiting HGHL-induced VCAM-1 expression (Yan et al. 2017), PI3K/AKT pathway in reducing the apoptosis of mesenchymal stem cells and cardiomyocytes (Yi et al. 2012, Hou et al. 2014), and cAMP/PKA pathway in promoting testosterone production in Leydig cells (Otani et al. 2012), have been reported. The AKT/mTOR pathway is important for cell growth and survival in response to growth factors and for primordial follicle activation and granulosa cell proliferation and apoptosis (Yaba et al. 2008, Yu et al. 2011, Hsueh 2014, Wen et al. 2015). We have demonstrated the FSH-induced phosphorylation of AKT and mTOR in granulosa cells, which is consistent with the findings of previous reports (Alam et al. 2004, Chen et al. 2007). To the best of our knowledge, the interactions between C1QTNF3 and mTOR have not been evaluated to date in other cell types. Our study is the first to demonstrate that C1QTNF3 activates mTOR and its downstream signaling. After mTOR activation, mTORC1 (rapamycin-sensitive mTOR complex 1) initiates the phosphorylation of p70S6K and 4EBP1 (Ponticelli 2004). This signaling cascade effect was detected in the cultured ovarian explants after the challenges with FSH and/or C1QTNF3 in this study. p70S6K phosphorylation supports cell cycle progression at the G1 stage by regulating protein synthesis (Ponticelli 2004, Song et al. 2007). Like p70S6K phosphorylation, G1/S stage cell cycle marker CCND2 was upregulated by FSH and C1QTNF3. Our research suggested that the effect of C1QTNF3 was similar to that of FSH in terms of the phosphorylation of AKT, mTOR and p70S6K and the upregulation of CCND2 expression. Although C1QTNF3 significantly enhanced the effects of FSH on AKT and mTOR phosphorylation, the synergistic effect of C1QTNF3 on FSH was not detected for p70S6K phosphorylation or the CCND2 increase. We have deduced that the effect of C1QTNF3 on p70S6K phosphorylation may be variable in different follicular cell types as C1QTNF3 was detected in oocytes and granulosa cells. Phosphorylated p70S6K reportedly induces oocyte (Sobinoff et al. 2013) and granulosa cell growth (Yu et al. 2011). Granulosa cell proliferation in the MTS assays indicates that the effects of C1QTNF3 on promoting follicular development were partially mediated through granulosa cells. However, the inconsistency of the effects of FSH plus C1QTNF3 on p70S6K phosphorylation and proliferation between the ovarian explants and granulosa cells suggests that C1QTNF3 may have different mechanisms in other follicle cell types. The phosphorylated form of 4EBP1 releases subunit eukaryotic initiation factor 4E (elF4F) to stimulate translation. The loss of the mTOR phosphorylation of 4EBP1 results in 4EBP1 binding to elF4F, leads to a general inhibition of translation (Gingras et al. 2001). In this study, the C1QTNF3 and FSH combination treatment induced a sharp reduction in 4EBP1 phosphorylation compared the FSH or C1QTNF3 treatment alone. Meanwhile, the cleaved CASP3 levels also significantly decreased with the combination treatment, with the total CASP3 levels remaining relatively stable. We presume that there may be a correlation between the reduction in 4EBP1 phosphorylation and the decrease in cleaved CASP3 levels. Cleaved CASP3 is a marker of apoptosis. The decrease in cleaved CASP3 indicated that C1QTNF3 enhanced the effect of $\mathrm{FSH}$ against granulosa cell apoptosis. AKT is phosphorylated during the C1QTNF3mediated protection of mesenchymal stem cells and cardiomyocytes against apoptosis (Yi et al. 2012, Hou et al. 2014). In this study, we have deduced that the anti-apoptosis effect of C1QTNF3 may occur through the AKT/mTOR signaling pathway, mostly via reduced 4EBP1 phosphorylation.

PCOS, the most common cause of anovulatory infertility, represents a state of hormonal dysregulation, disrupted ovarian follicle dynamics, and subsequent oligo-ovulation or anovulation. Previous studies have shown that serum and omental adipose tissue CTRP3 levels are lower in women with PCOS (Tan et al. 2013), revealing an important connection between the CTRP3 level and the pathophysiology of PCOS. The intraovarian expression of C1QTNF3 was significantly decreased by excess androgen in healthy granulosa cells and in the polycystic ovaries of our DHEA-induced PCOS mouse model. A characteristic morphological feature of PCOS is the arrested growth of large antral follicles. Granulosa cell apoptosis plays a pivotal role in the development of the cyst structure in PCOS (Franks et al. 2008). The C1QTNF3 reduction in the ovary of the PCOS mouse model and the augmenting effect of C1QTNF3 on FSHmediated anti-apoptosis may provide a clue toward elucidating the causal relationship between C1QTNF3 and PCOS.

In summary, C1QTNF3 is mainly expressed in the granulosa cells and oocytes of growing follicles, especially in antral follicles, and its expression is decreased in atretic follicles. C1QTNF3 accelerated FSH-induced follicular development and ovarian growth via the initiation of AKT/mTOR activation, which was accompanied by increased proliferation associated with CCND2 expression and a decreasing the level of cleaved CASP3. C1QTNF3 possessed the potential to promote the proliferation and anti-apoptosis of granulosa cells. However, the intercellular pathways of C1QTNF3 in terms of granulosa cell proliferation and apoptosis remain elusive. Although C1qtnf3 is expressed in the ovarian cells, C1QTNF3 is also a circulating adipokine. Whether the intraovarian C1QTNF3 protein is originated from endocrine and paracrine by adipose tissues or paracrine and autocrine by follicular cells is still unknown. As an intraovarian factor involving in folliculogenesis, the mechanisms through which C1QTNF3 functions needs further study. 


\section{Declaration of interest}

The authors declare that there is no conflict of interest that could be perceived as prejudicing the impartiality of the research reported.

\section{Funding}

This work was supported by the National Natural Science Foundation of China (30900232); the Natural Science Foundation of Guangdong Province, China (8451063201000105); the Fundamental Research Funds for the Central Universities (21610202), the Excellent Doctoral Thesis Foundation of Guangdong Province, China (sybzzxm201033) and the Major Research plan of the National Natural Science Foundation of China (91649203).

\section{Acknowledgements}

The authors thank Prof. Aaron J. Hsueh and Dr Yuan Cheng of Stanford University School of Medicine for their technical and intellectual contributions.

\section{References}

Abedini A, Zamberlam G, Boerboom D \& Price CA 2015 Non-canonical WNT5A is a potential regulator of granulosa cell function in cattle. Molecular and Cellular Endocrinology 403 39-45. (https://doi. org/10.1016/j.mce.2015.01.017)

Ajuwon KM \& Spurlock ME 2005 Adiponectin inhibits LPS-induced NFkappaB activation and IL- 6 production and increases PPARgamma2 expression in adipocytes. American Journal of Physiology: Regulatory, Integrative and Comparative Physiology 288 R1220-R1225. (https://doi. org/10.1152/ajpregu.00397.2004)

Akiyama H, Furukawa S, Wakisaka S \& Maeda T 2007 CTRP3/cartducin promotes proliferation and migration of endothelial cells. Molecular and Cellular Biochemistry 304 243-248. (https://doi.org/10.1007/s11010007-9506-6)

Alam H, Maizels ET, Park Y, Ghaey S, Feiger ZJ, Chandel NS \& HunzickerDunn M 2004 Follicle-stimulating hormone activation of hypoxiainducible factor-1 by the phosphatidylinositol 3-kinase/AKT/Ras homolog enriched in brain (Rheb)/mammalian target of rapamycin (mTOR) pathway is necessary for induction of select protein markers of follicular differentiation. Journal of Biological Chemistry 279 19431-19440. (https://doi.org/10.1074/jbc.M401235200)

Ban B, Bai B, Zhang MM, Hu JM, Ramanjaneya M, Tan BK \& Chen J 2014 Low serum Cartonectin/CTRP3 concentrations in newly diagnosed type 2 diabetes mellitus: in vivo regulation of cartonectin by glucose. PLOS ONE 9 e112931. (https://doi.org/10.1371/journal.pone.0112931)

Chabrolle C, Tosca L \& Dupont J 2007 Regulation of adiponectin and its receptors in rat ovary by human chorionic gonadotrophin treatment and potential involvement of adiponectin in granulosa cell steroidogenesis. Reproduction 133 719-731. (https://doi.org/10.1530/REP-06-0244)

Chen YJ, Hsiao PW, Lee MT, Mason JI, Ke FC \& Hwang JJ 2007 Interplay of PI3K and CAMP/PKA signaling, and rapamycin-hypersensitivity in TGFbeta1 enhancement of FSH-stimulated steroidogenesis in rat ovarian granulosa cells. Journal of Endocrinology 192 405-419. (https://doi. org/10.1677/JOE-06-0076)

Cheng L, Shi H, Jin Y, Li X, Pan J, Lai Y, Lin Y, Jin Y, Roy G, Zhao A et al. 2016 Adiponectin deficiency leads to female subfertility and ovarian dysfunctions in mice. Endocrinology 157 4875-4887. (https://doi. org/10.1210/en.2015-2080)

Cheng C, Yu S, Kong R, Yuan Q, Ma Y, Yang W, Cao G \& Xie L 2017 CTRP3 attenuates hepatic stellate cell activation through transforming growth factor-beta/Smad signaling pathway. Biomedicine and Pharmacotherapy 89 1387-1391. (https://doi.org/10.1016/j.biopha.2017.03.021)
Deng W, Li C, Zhang Y, Zhao J, Yang M, Tian M, Li L, Zheng Y, Chen B \& Yang G 2015 Serum C1q/TNF-related protein-3 (CTRP3) levels are decreased in obesity and hypertension and are negatively correlated with parameters of insulin resistance. Diabetology and Metabolic Syndrome 7 33. (https://doi.org/10.1186/s13098-015-0029-0)

Durlinger AL, Gruijters MJ, Kramer P, Karels B, Kumar TR, Matzuk MM, Rose UM, de Jong FH, Uilenbroek JT, Grootegoed JA et al. 2001 AntiMullerian hormone attenuates the effects of FSH on follicle development in the mouse ovary. Endocrinology 142 4891-4899. (https://doi. org/10.1210/endo.142.11.8486)

Escobar ML, Echeverria OM, Ortiz R \& Vazquez-Nin GH 2008 Combined apoptosis and autophagy, the process that eliminates the oocytes of atretic follicles in immature rats. Apoptosis 13 1253-1266. (https://doi. org/10.1007/s10495-008-0248-z)

Franks S, Stark J \& Hardy K 2008 Follicle dynamics and anovulation in polycystic ovary syndrome. Human Reproduction Update 14 367-378. (https://doi.org/10.1093/humupd/dmn015)

Gingras AC, Raught B \& Sonenberg N 2001 Regulation of translation initiation by FRAP/mTOR. Genes and Development 15 807-826. (https://doi.org/10.1101/gad.887201)

Hou M, Liu JJ, Liu F, Liu K \& Yu B 2014 C1q tumor necrosis factor-related protein-3 protects mesenchymal stem cells against hypoxia- and serum deprivation-induced apoptosis through the phosphoinositide 3-kinase/ Akt pathway. International Journal of Molecular Medicine 33 97-104. (https://doi.org/10.3892/ijmm.2013.1550)

Hou Q, Lin J, Huang W, Li M, Feng J \& Mao X 2015 CTRP3 stimulates proliferation and anti-apoptosis of prostate cells through PKC signaling pathways. PLOS ONE 10 e0134006. (https://doi.org/10.1371/journal. pone.0134006)

Hsueh AJW 2014 Fertility: the role of mTOR signaling and KIT ligand. Current Biology 24 R1040-R1042. (https://doi.org/10.1016/j. cub.2014.09.033)

Hsueh AJW, Kawamura K, Cheng Y \& Fauser BCJM 2015 Intraovarian control of early folliculogenesis. Endocrine Reviews 36 1-24. (https:// doi.org/10.1210/er.2014-1020)

Hulas-Stasiak M, Dobrowolski P \& Tomaszewska E 2016 Prenatally administered dexamethasone impairs folliculogenesis in spiny mouse offspring. Reproduction, Fertility and Development 28 1038-1048. (https://doi.org/10.1071/RD14224)

Johnson J, Canning J, Kaneko T, Pru JK \& Tilly JL 2004 Germline stem cells and follicular renewal in the postnatal mammalian ovary. Nature $\mathbf{4 2 8}$ 145-150. (https://doi.org/10.1038/nature02316)

Kumar TR, Wang Y, Lu N \& Matzuk MM 1997 Follicle stimulating hormone is required for ovarian follicle maturation but not male fertility. Nature Genetics 15 201-204. (https://doi.org/10.1038/ng0297-201)

Li Y, Ozment T, Wright GL \& Peterson JM 2016 Identification of putative receptors for the novel adipokine CTRP3 using ligand-receptor capture technology. PLoS ONE 11 e0164593. (https://doi.org/10.1371/journal. pone.0164593)

Maeda T \& Wakisaka S 2010 CTRP3/cartducin is induced by transforming growth factor-beta 1 and promotes vascular smooth muscle cell proliferation. Cell Biology International 34 261-266. (https://doi. org/10.1042/CBI20090043)

Maeda T, Jikko A, Abe M, Yokohama-Tamaki T, Akiyama H, Furukawa S, Takigawa M \& Wakisaka S 2006 Cartducin, a paralog of Acrp30/ adiponectin, is induced during chondrogenic differentiation and promotes proliferation of chondrogenic precursors and chondrocytes. Journal of Cellular Physiology 206 537-544. (https://doi.org/10.1002/jcp.20493)

Messinis IE 2006 Ovarian feedback, mechanism of action and possible clinical implications. Human Reproduction Update 12 557-571. (https://doi.org/10.1093/humupd/dml020)

Motta AB 2010 Dehydroepiandrosterone to induce murine models for the study of polycystic ovary syndrome. Journal of Steroid Biochemistry and Molecular Biology 119 105-111. (https://doi.org/10.1016/j. jsbmb.2010.02.015)

Myers M, Britt KL, Wreford NG, Ebling FJ \& Kerr JB 2004 Methods for quantifying follicular numbers within the mouse ovary. Reproduction 127 569-580. (https://doi.org/10.1530/rep.1.00095)

Otani M, Kogo M, Furukawa S, Wakisaka S \& Maeda T 2012 The adiponectin paralog C1q/TNF-related protein 3 (CTRP3) stimulates testosterone production through the CAMP/PKA signaling pathway. Cytokine 58 238-244. (https://doi.org/10.1016/j.cyto.2012.01.018) 
Otani M, Furukawa S, Wakisaka S \& Maeda T 2015 A novel adipokine C1q/TNF-related protein 3 is expressed in developing skeletal muscle and controls myoblast proliferation and differentiation. Molecular and Cellular Biochemistry 409 271-282. (https://doi.org/10.1007/s11010015-2531-y)

Peterson JM, Wei ZK \& Wong GW 2010 C1q/TNF-related protein-3 (CTRP3), a novel adipokine that regulates hepatic glucose output. Journal of Biological Chemistry 285 39691-39701. (https://doi.org/10.1074/jbc. M110.180695)

Peterson JM, Seldin MM, Wei ZK, Aja S \& Wong GW 2013 CTRP3 attenuates diet-induced hepatic steatosis by regulating triglyceride metabolism. American Journal of Physiology-Gastrointestinal and Liver Physiology 305 G214-G224. (https://doi.org/10.1152/ajpgi.00102.2013)

Ponticelli C 2004 The pleiotropic effects of mTor inhibitors. Journal of the American Society of Nephrology 17 762-768.

Robker RL \& Richards JS 1998 Hormone-induced proliferation and differentiation of granulosa cells: a coordinated balance of the cell cycle regulators cyclin D2 and p27Kip1. Molecular Endocrinology 12 924-940. (https://doi.org/10.1210/mend.12.7.0138)

Sato Y, Cheng Y, Kawamura K, Takae S \& Hsueh AJ 2012 C-type natriuretic peptide stimulates ovarian follicle development. Molecular Endocrinology 26 1158-1166. (https://doi.org/10.1210/me.2012-1027)

Schaffler A \& Buechler C 2012 CTRP family: linking immunity to metabolism. Trends in Endocrinology and Metabolism 23 194-204. (https://doi.org/10.1016/j.tem.2011.12.003)

Schmid A, Kopp A, Hanses F, Karrasch T \& Schaffler A 2014 C1q/TNFrelated protein-3 (CTRP-3) attenuates lipopolysaccharide (LPS)-induced systemic inflammation and adipose tissue Erk-1/-2 phosphorylation in mice in vivo. Biochemical and Biophysical Research Communications 452 8-13. (https://doi.org/10.1016/j.bbrc.2014.06.054)

Shibata R, Sato K, Pimentel DR, Takemura Y, Kihara S, Ohashi K, Funahashi T, Ouchi N \& Walsh K 2005 Adiponectin protects against myocardial ischemia-reperfusion injury through AMPK- and COX-2dependent mechanisms. Nature Medicine 11 1096-1103. (https://doi. org/10.1038/nm1295)

Sobinoff AP, Sutherland JM \& McLaughlin EA 2013 Intracellular signalling during female gametogenesis. Molecular Human Reproduction 19 265-278. (https://doi.org/10.1093/molehr/gas065)

Song J, Salek-Ardakani S, So T \& Croft M 2007 The kinases aurora B and mTOR regulate the G1-S cell cycle progression of T lymphocytes. Nature Immunology 8 64-73. (https://doi.org/10.1038/ni1413)

Tabandeh MR, Hosseini A, Saeb M, Kafi M \& Saeb S 2010 Changes in the gene expression of adiponectin and adiponectin receptors (AdipoR1 and AdipoR2) in ovarian follicular cells of dairy cow at different stages of development. Theriogenology 73 659-669. (https://doi.org/10.1016/j. theriogenology.2009.11.006)

Tan BK, Chen J, Hu J, Amar O, Mattu HS, Adya R, Patel V, Ramanjaneya M, Lehnert H \& Randeva HS 2013 Metformin increases the novel adipokine cartonectin/CTRP3 in women with polycystic ovary syndrome. Journal of Clinical Endocrinology and Metabolism 98 E1891-E1900. (https://doi. org/10.1210/jc.2013-2227)

Tao T, Xu B \& Liu W 2013 Ovarian HMW adiponectin is associated with folliculogenesis in women with polycystic ovary syndrome. Reproductive Biology and Endocrinology 11 99. (https://doi.org/10.1186/1477-782711-99)

Tian XQ, Yang YJ, Li Q, Huang PS, Li XD, Jin C, Qi K, Jiang LP \& Chen GH 2016 Globular adiponectin inhibits the apoptosis of mesenchymal stem cells induced by hypoxia and serum deprivation via the adipoR1mediated pathway. Cellular Physiology and Biochemistry 38 909-925. (https://doi.org/10.1159/000443044)

Uslu B, Dioguardi CC, Haynes M, Miao DQ, Kurus M, Hoffman G \& Johnson J 2017 Quantifying growing versus non-growing ovarian follicles in the mouse. Journal of Ovarian Research 10 3. (https://doi. org/10.1186/s13048-016-0296-x)

Wen R, Hu S, Xiao Q, Han C, Gan C, Gou H, Liu H, Li L, Xu H, He H et al. 2015 Leptin exerts proliferative and anti-apoptotic effects on goose granulosa cells through the PI3K/Akt/mTOR signaling pathway. Journal of Steroid Biochemistry and Molecular Biology 149 70-79. (https://doi. org/10.1016/j.jsbmb.2015.01.001)

Wolf RM, Steele KE, Peterson LA, Magnuson TH, Schweitzer MA \& Wong GW 2015 Lower circulating C1q/TNF-related protein-3 (CTRP3) levels are associated with obesity: a cross-sectional study. PLOS ONE 10 e0133955. (https://doi.org/10.1371/journal.pone.0133955)

Wong GW, Wang J, Hug C, Tsao TS \& Lodish HF 2004 A family of Acrp30/adiponectin structural and functional paralogs. PNAS $\mathbf{1 0 1}$ 10302-10307. (https://doi.org/10.1073/pnas.0403760101)

Wu C, Lin F, Qiu S \& Jiang Z 2014 The characterization of obese polycystic ovary syndrome rat model suitable for exercise intervention. PLOS ONE 9 e99155. (https://doi.org/10.1371/journal.pone.0099155)

Xu A, Wang Y, Keshaw H, Xu LY, Lam KS \& Cooper GJ 2003 The fat-derived hormone adiponectin alleviates alcoholic and nonalcoholic fatty liver diseases in mice. Journal of Clinical Investigation 112 91-100. (https:// doi.org/10.1172/JCl200317797)

Yaba A, Bianchi V, Borini A \& Johnson J 2008 A putative mitotic checkpoint dependent on mTOR function controls cell proliferation and survival in ovarian granulosa cells. Reproductive Sciences 15 128-138. (https://doi. org/10.1177/1933719107312037)

Yan Z, Zhao J, Gan L, Zhang Y, Guo R, Cao X, Lau WB, Ma X \& Wang Y 2017 CTRP3 is a novel biomarker for diabetic retinopathy and inhibits HGHLinduced VCAM-1 expression in an AMPK-dependent manner. PLOS ONE 12 e0178253. (https://doi.org/10.1371/journal.pone.0178253)

Yi W, Sun Y, Yuan YX, Lau WB, Zheng QJ, Wang XL, Wang YJ, Shang XY, Gao EH, Koch WJ et al. 2012 C1q/tumor necrosis factor-related protein-3, a newly identified adipokine, is a novel antiapoptotic, proangiogenic, and cardioprotective molecule in the ischemic mouse heart. Circulation 125 3159-3169. ( https://doi.org/10.1161/ CIRCULATIONAHA.112.099937)

Yu J, Yaba A, Kasiman C, Thomson T \& Johnson J 2011 mTOR controls ovarian follicle growth by regulating granulosa cell proliferation. PLoS ONE 6 e21415. (https://doi.org/10.1371/journal.pone.0021415)

Zhang CL, Chen ZJ, Feng H, Zhao Q, Cao YP, Li L, Wang JY, Zhang Y \& Wu LL 2017 C1q/tumor necrosis factor-related protein-3 enhances the contractility of cardiomyocyte by increasing calcium sensitivity. Cell Calcium 66 90-97. (https://doi.org/10.1016/j.ceca.2017.06.009)

Received 3 June 2017

First decision 29 June 2017

Revised manuscript received 4 January 2018

Accepted 1 February 2018 